\title{
Staging/typing of Lewy body related $\alpha$-synuclein pathology: a study of the BrainNet Europe Consortium
}

\author{
Irina Alafuzoff · Paul G. Ince · Thomas Arzberger · Safa Al-Sarraj · Jeanne Bell · Istvan Bodi · \\ Nenad Bogdanovic · Orso Bugiani · Isidro Ferrer · Ellen Gelpi · Stephen Gentleman · Giorgio Giaccone • \\ James W. Ironside · Nikolaos Kavantzas • Andrew King • Penelope Korkolopoulou • Gábor G. Kovács · \\ David Meyronet · Camelia Monoranu · Piero Parchi - Laura Parkkinen · Efstratios Patsouris · \\ Wolfgang Roggendorf • Annemieke Rozemuller · Christine Stadelmann-Nessler • Nathalie Streichenberger · \\ Dietmar R. Thal · Hans Kretzschmar
}

Received: 2 February 2009/Revised: 17 March 2009/Accepted: 17 March 2009/Published online: 28 March 2009

(C) The Author(s) 2009. This article is published with open access at Springerlink.com

\begin{abstract}
When 22 members of the BrainNet Europe (BNE) consortium assessed 31 cases with $\alpha$-synuclein $(\alpha \mathrm{S})$ immunoreactive (IR) pathology applying the consensus protocol described by McKeith and colleagues in 2005, the inter-observer agreement was $80 \%$, being lowest in the limbic category $(73 \%)$. When applying the staging protocol described by Braak and colleagues in 2003, agreement was
\end{abstract}

I. Alafuzoff, P. Ince, J. Bell, J. Ironside, S. Gentleman, H. Kretzschmar did primary assessment of all cases; I. Alafuzoff, P. Ince the construction of the assessment recommendations. Each listed author carried out the assessment and contributed to manuscript revision.

\footnotetext{
A. Rozemuller

Netherlands Brain Bank, VU University Medical Center,

Amsterdam, The Netherlands

N. Kavantzas · P. Korkolopoulou · E. Patsouris

Department of Pathology, National and Capodistrian University

of Athens, Athens, Greece

I. Ferrer · E. Gelpi

Institut de Neuropatologia, Universitat de Barcelona,

Barcelona, Spain

P. Parchi

Dipartimento di Scienze Neurologiche, Università di Bologna,

Bologna, Italy

J. Bell $\cdot$ J. W. Ironside

Department of Pathology, University of Edinburgh,

Western General Hospital, Edinburgh, UK

C. Stadelmann-Nessler

Georg-August-Universitaet Goettingen, Göttingen, Germany

N. Bogdanovic

Department of Geriatrics, Karolinska Institutet,

Huddinge, Sweden
}

only $65 \%$, and in some cases as low as $36 \%$. When modifications of these strategies, i.e., McKeith's protocol by Leverenz and colleagues from 2009, Braak's staging by Müller and colleagues from 2005 were applied then the agreement increased to 78 and $82 \%$, respectively. In both of these modifications, a reduced number of anatomical regions/blocks are assessed and still in a substantial number of cases, the inter-observer agreement differed significantly. Over $80 \%$ agreement in both typing and staging of $\alpha \mathrm{S}$ pathology could be achieved when applying a new protocol, jointly designed by the BNE consortium. The BNE-protocol assessing $\alpha \mathrm{S}-\mathrm{IR}$ lesions in nine blocks

\section{Alafuzoff · L. Parkkinen}

Department of Neuroscience and Neurology, Kuopio University, Kuopio, Finland

\section{S. Gentleman}

Neuropathology Unit, Department of Clinical Neuroscience, Imperial College, London, UK

\section{S. Al-Sarraj · I. Bodi · A. King}

Department of Clinical Neuropathology,

London Institute of Psychiatry, London, UK

D. Meyronet · N. Streichenberger

Faculté de Médecine Laennec Hospices Civils de Lyon,

Centre de Neuropathologie et Pathologie-Est,

Université Lyon 1, Lyon, France

O. Bugiani - G. Giaccone

Fondazione IRCCS Istituto Neurologico Carlo Besta,

Milan, Italy

T. Arzberger $\cdot$ H. Kretzschmar

Centre for Neuropathology and Prion Research,

Ludwig-Maximilians-University, Munich, Germany 
offered advantages over the previous modified protocols because the agreement between the 22 observers was over $80 \%$ in most cases. Furthermore, in the BNE-protocol, the $\alpha \mathrm{S}$ pathology is assessed as being present or absent and thus the quality of staining and the assessment of the severity of $\alpha \mathrm{S}$-IR pathology do not alter the inter-observer agreement, contrary to other assessment strategies. To reach these high agreement rates an entity of amygdalapredominant category was incorporated. In conclusion, here we report a protocol for assessing $\alpha \mathrm{S}$ pathology that can achieve a high inter-observer agreement for both the assignment to brainstem, limbic, neocortical and amygdala-predominant categories of synucleinopathy and the Braak stages.

\section{Introduction}

While evaluating postmortem brains for signs of neurodegeneration, the pathologist has to assess numerous pathologies, both those that one might expect to find based on the clinical presentation and those that might be found based on frequent findings of comorbidity. Furthermore, one must also consider the high rate of unexpected pathologies that characterise the ageing brain. Operationalized criteria have been developed in order to make the assessment of pathology more reliable and reproducible. These criteria have, however, rarely been validated even for some of the pathologies that are both common and carry a clinical significance $[1,18,21]$. The major prerequisites for recommendable operationalized criteria are clarity, reproducibility and validation.

\section{P. G. Ince}

Department of Neurosciences, University of Sheffield,

Sheffield, UK

D. R. Thal

Laboratory of Neuropathology, Institute of Pathology,

University of Ulm, Ulm, Germany

\section{Alafuzoff}

Rudbeck Laboratory, Department of Genetics and Pathology, Uppsala University, Uppsala, Sweden

G. G. Kovács

Medical University of Vienna, Vienna, Austria

C. Monoranu · W. Roggendorf

Abteilung fur Neuropathologie, Pathologisches Institut der Universität Würzburg, Würzburg, Germany

\section{Alafuzoff ( $($ )}

Department of Clinical Medicine, Kuopio University, Kuopio, Finland

e-mail: Irina.Alafuzoff@genpat.uu.se; irina.alafuzoff@uku.fi URL: http://www.brainnet-europe.org/
Already in 1984, Kosaka and colleagues [17] made the first attempt to standardize the assessment of brain pathology associated with dementia with Lewy bodies (DLB). DLB cases were divided into brainstem, limbic and neocortical subtypes. This division formed the basis of the clinical concept that in Lewy body disorders (LBD) the clinical manifestation depends on the anatomical distribution of the pathology [11, 13, 17, 19, 25]. More detailed instructions for diagnostic procedures when dealing with DLB, including details for sampling of brain, staining of sections, assessment and diagnostic rating of lesions were published in 1996 by the Consortium on DLB International Workshop [19]. These consensus recommendations were based on work carried out assessing either hematoxylin-eosin stained sections or applying ubiquitin immunohistochemistry (IHC).

In 1993, Ueda and colleagues identified a protein they referred to as the non-A $\beta$ component of Alzheimer's amyloid, and later in 1997 Polymeropoulos and colleagues demonstrated that this protein, $\alpha$-synuclein $(\alpha S)$, was central to the neurodegenerative process in DLB and Parkinson's disease [26, 30]. The era of $\alpha \mathrm{S}$ IHC was subsequently initiated by the report that $\mathrm{LBs}$ and LB associated neurites (LN) were consistently labelled with $\alpha \mathrm{S}$ across this spectrum of disorders [28].

In 2003, Braak and colleagues, following the concept delineated by Kosaka and colleagues and applying $\alpha \mathrm{S}$ IHC, described a staging hierarchy of LB related pathology [5, 17] (Table 1a). These authors emphasised that $\alpha \mathrm{S}$ immunoreactive (IR) pathology initially occurs in the dorsal motor nucleus of vagus and then progresses in an orderly caudal to rostral direction, ultimately reaching the neocortex. Subsequently in 2005, the DLB consortium revised their original protocol and recommended $\alpha \mathrm{S}$ IHC as the preferred method of pathological evaluation, added new brain regions and devised a detailed scoring strategy for the assessment of the labelled lesions [19, 20] (Table 1c).

Since then, several studies have been published using $\alpha \mathrm{S}$ IHC in combination with the two most commonly used classification strategies usually referred to as Braak's staging and McKeith's typing of LB disease related pathology [5, 20]. When assessing a large number of brains, many of these studies indicate that $\alpha \mathrm{S}$ pathology is not always present as would be predicted according to the hypothesis of anatomical hierarchy that underpins these protocols. Thus, some cases remain unclassifiable (17$51 \%$ ) if one strictly follows these current assessment recommendations [13, 18, 22, 23, 31]. Interestingly, in 2008, Leverenz and colleagues reported that they were able to increase the number of classifiable cases from 51 to $96 \%$ by modifying the classification strategy originally described by McKeith and colleagues (Table 1d) [18, 20]. The modifications consisted of a reduction in the number of regions to be examined, more variability in the assessment 
Table 1 Original and modified Braak staging and McKeith typing of Lewy body (LB) related $\alpha$-synuclein ( $\alpha$ S) immunoreactive (IR) pathology a. Braak staging of LB related pathology from Braak and colleagues from $2003[5]^{\mathrm{a}}$

\begin{tabular}{|c|c|c|c|c|c|c|c|c|c|c|c|c|c|c|c|}
\hline Stage & $\mathrm{dmV}$ & irz & $\mathrm{LC}$ & $\mathrm{R}$ & SN & $\mathrm{AC}$ & $\mathrm{nbM}$ & CA2 & transent $\mathrm{cx}(\mathrm{mc})$ & TO cx (mc) & Ins cx (hc) & $\mathrm{GC}(\mathrm{hc})$ & $\mathrm{T}$ cx $(\mathrm{hc})$ & $\mathrm{F} \mathrm{cx}(\mathrm{fc})$ & $P c x(f c)$ \\
\hline 1 & $1-2$ & IR & & & & & & & & & & & & & \\
\hline 2 & $1-2$ & IR & $0-2$ & $1-2$ & & & & & & & & & & & \\
\hline 3 & $1-3$ & IR & $1-3$ & $1-2$ & $1-3$ & & $1-3$ & $0-2$ & & & & & & & \\
\hline 4 & $2-3$ & IR & $2-3$ & $2-3$ & $2-3$ & IR & $1-3$ & $1-2$ & $1-2$ & $1-2$ & & & & & \\
\hline 5 & $2-3$ & IR & $2-3$ & $2-3$ & $2-3$ & IR & $2-3$ & $1-3$ & 2 & 2 & 1 & 1 & 1 & & \\
\hline 6 & 3 & IR & $2-3$ & $2-3$ & 3 & IR & 3 & $1-3$ & $2-3$ & $2-3$ & 2 & 2 & 2 & 1 & 1 \\
\hline
\end{tabular}

b. Braak staging of Lewy-body related pathology as applied in Müller and colleagues from 2005 [21]

\begin{tabular}{llllllll}
\hline Stage & dmV or irz & LC & R & SN & CA2 & transent cs & T cx \\
\hline 1 & $\geq+$ & & & & & & \\
2 & $\geq+$ & $\geq+$ & & & & & \\
3 & $\geq+$ & $\geq+$ & $\geq+$ & $\geq+$ & & & \\
4 & $\geq+$ & $\geq+$ & $\geq+$ & $\geq+$ & $\geq+$ & $\geq+$ & $\geq+$ \\
5 & $\geq+$ & $\geq+$ & $\geq+$ & $\geq+$ & $\geq+$ & $\geq+$ & $\geq++$ \\
6 & $\geq+$ & $\geq+$ & $\geq+$ & $\geq+$ & $\geq+$ & $\geq+$ & \\
\end{tabular}

c. McKeith typing of LB related pathology from McKeith and colleagues from 2005 [20] ${ }^{\mathrm{c}}$

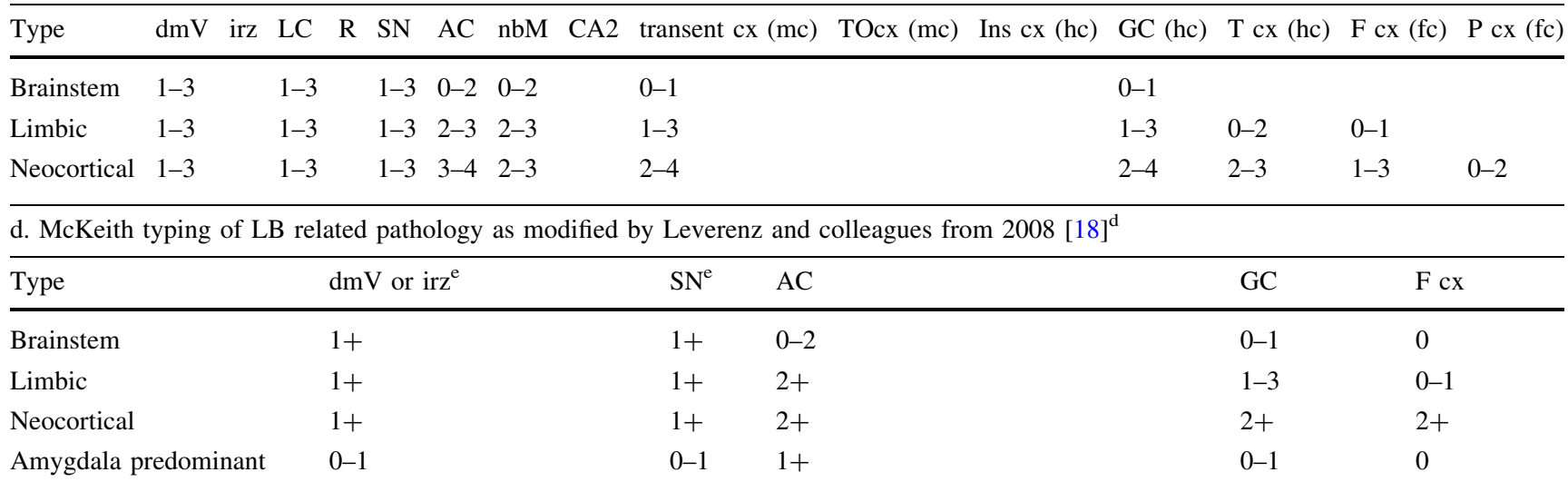

Anatomical regions listed here are those that are recommended to be assessed by Braak and colleagues (Table 1). Abbreviations of anatomical regions: $d m V$ dorsal motor nucleus of Vagus, irz intermediate reticular zone, $L C$ locus coeruleus, $R$ raphe, $S N$ substantia nigra, $A C$ amygdala, $n b M$ nucleus basalis of Meynert, $C A 2$ cornu Ammonis of hippocampus region 2, transent $c x$ transentorhinal region, TO $c x$ temporo-occipital cortex, Ins $c x$ insular cortex, $G C$ gyrus cinguli, $T c x$ temporal cortex, $F c x$ frontal cortex, $P c x$ parietal cortex, $f c$ first order sensory association areas and premotor areas and/or primary sensory and motor field of neocortex, $h c$ high order sensory association areas and prefrontal areas of the neocortex, $m c$ mesocortex

${ }^{\text {a }}$ In the original publication, results given in the table as slight $(+)$, moderate $(++)$ and severe $(+++) \alpha$ S-IR, corresponding here with 1,2 and 3 , respectively. Labelling in AC and irz is mentioned in the text as IR noted

${ }^{b}$ In the publication, presence $(\geq+)$ or absence of $\alpha S$-IR is assessed

c The extent of $\alpha \mathrm{S}$-IR pathology: $1=$ sparse LBs or neurites, $2=>1 \mathrm{LB} /$ high power field and sparse neurites, $3=\geq 4 \mathrm{LBs}$ and scattered neurites in low power field, $4=$ numerous LBs and neurites

${ }^{\mathrm{d}}$ The extent of $\alpha \mathrm{S}$-IR pathology as given above. Note, a case that fulfills criteria for two categories should be assigned to the more neuroanatomically rostral category and an amygdala predominant type is added

e Regarding brainstem, limbic and neocortical McKeith type modified by Leverenz and colleagues [13] in medulla (dmV, irz) and SN aS-IR pathology at the level of $1+$ noted in either region and in the amygdala predominant $\alpha$ S-IR pathology at the level of $0-1$ noted in both regions

of the severity of LB-related pathology and the addition of an amygdala-predominant category of synucleinopathy.

Only a few reports have been published assessing the reproducibility of the recommended staging strategies. The first report regarding inter-rater agreement showed that high agreement was reached when six observers rated five brain regions in 21 cases following a somewhat simplified version of the original strategy proposed by Braak and 
colleagues [5, 21] (Table 1b). Later in 2008, two neuropathologists reached a 58\% agreement assessing 89 cases with LB-related pathology. Each case was represented by 9 brain regions and was classified according to the original McKeith protocol $[18,20]$ (Table 1c). The level of agreement between these two assessors increased to $83 \%$ when the proposed modified McKeith typing strategy was applied [18] (Table 1d).

The objectives of this study were to assess inter-rater agreement among 22 neuropathologists with two strategies, the original staging strategy of Braak and colleagues and the original typing protocol of McKeith and colleagues [5, 20]. The study sought to identify the pitfalls that impact on the inter-observer agreement to produce a staging strategy yielding the highest possible agreement in an interlaboratory setting combining many participants with varying experiences of assessing the pathology of DLB. Furthermore, we evaluated the reproducibility of both the simplified Braak's staging previously utilized in the interrater trial by Müller and colleagues and the recently launched modification of the McKeith's typing strategy proposed by Leverenz and colleagues [18, 21]. Finally, we applied the new modified protocols designed within BrainNet Europe (BNE) to assimilate the strength of Braak's and McKeith's strategies with other recent advances in $\alpha \mathrm{S}$ pathology.

\section{Materials and methods}

The general working order is summarized in Fig. 1.

\section{Sampling of material}

Thirty-one cases were included and the sampling of the blocks was carried out by one neuropathologist. The selection of the anatomical regions included in this study was based on the currently commonly used assessment strategies, i.e. Braak's staging and McKeith's typing of LB disease related pathology [5, 20]. Furthermore, only neuroanatomical regions that are known to be easily recognizable even by an observer lacking substantial training in neuroanatomy were included [2] (Fig. 2). The cases included were selected based on that they displayed $\alpha \mathrm{S}-\mathrm{IR}$

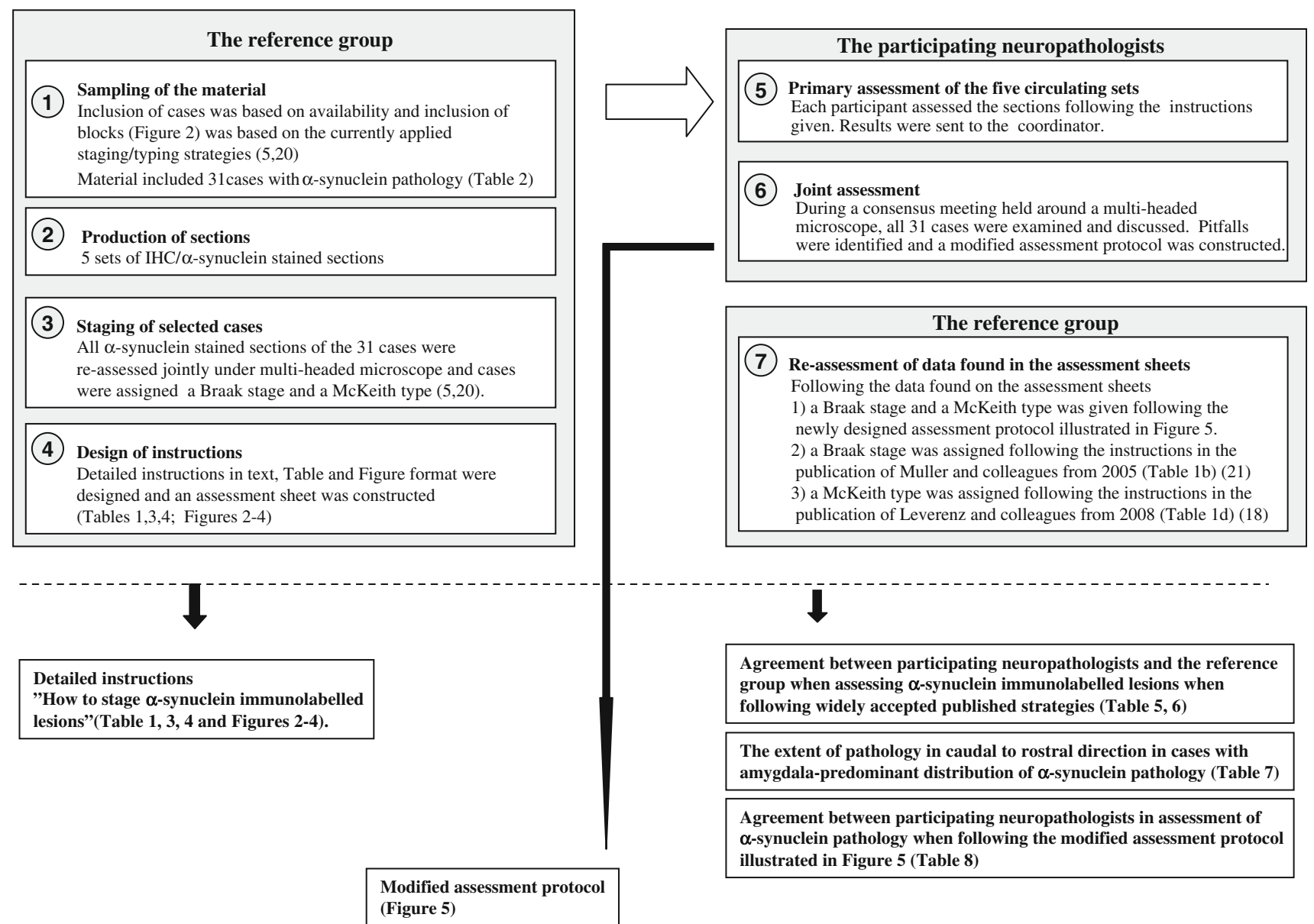

Fig. 1 Flowchart 
Fig. 2 Eight of the ten anatomical regions sampled and the scanned figures of all sections with delineation* of structures to be assessed are illustrated. 1-medulla with dorsal motor nucleus of vagus* and intermediate reticular zone*; 2-pons with locus ceruleus* and dorsal raphe nucleus*; 3-midbrain with substantia nigra, pars compacta*; 4-basal forebrain with amygdaloid nucleus* and nucleus basalis of Meynert*; 5 -striatum with insular cortex*; 6-hippocampus at the level of lateral geniculate nucleus with CA2 region* and temporooccipital cortex*; 7-gyrus cinguli grey matter, 8-temporal cortex, superior and middle* temporal gyrus, grey matter; 9- frontal cortex, Brodmann area 9- and 10- parietal cortex, Brodmann area 39/40
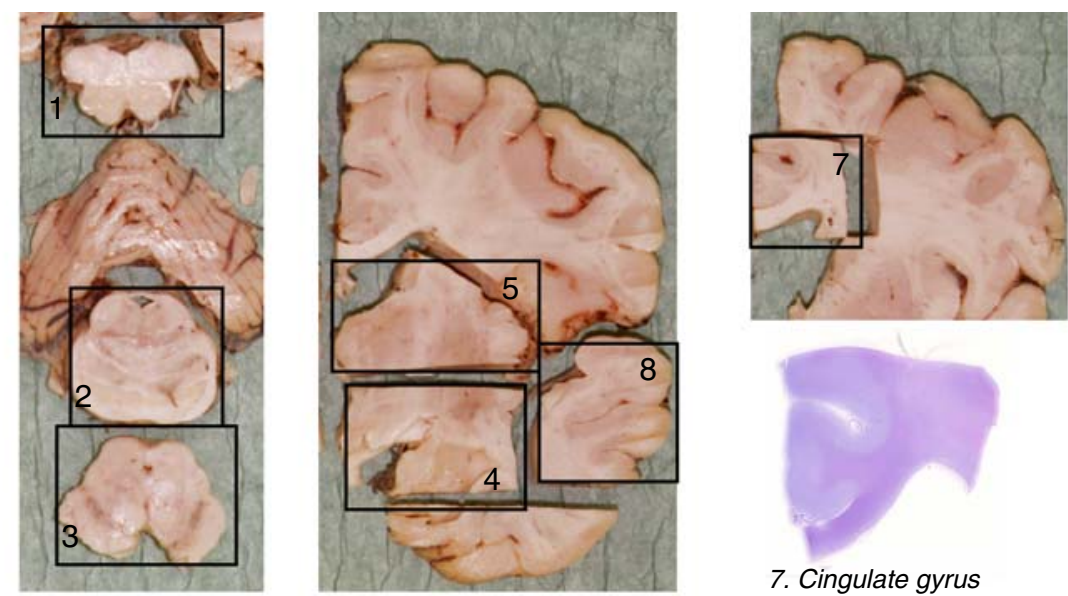

7. Cingulate gyrus
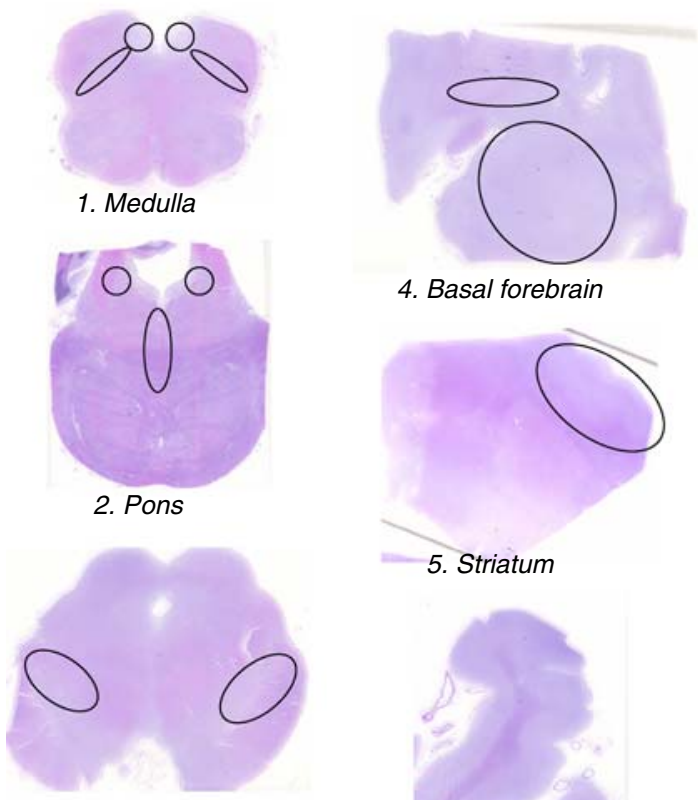

3. Midbrain
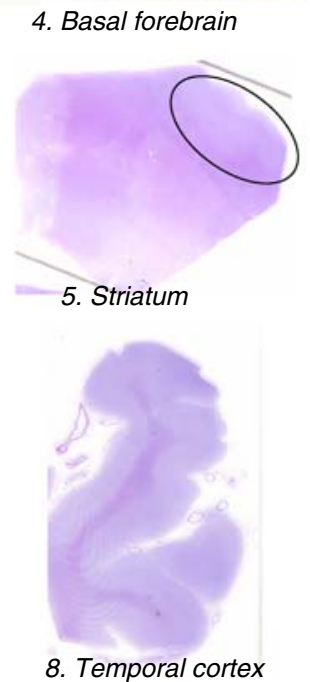
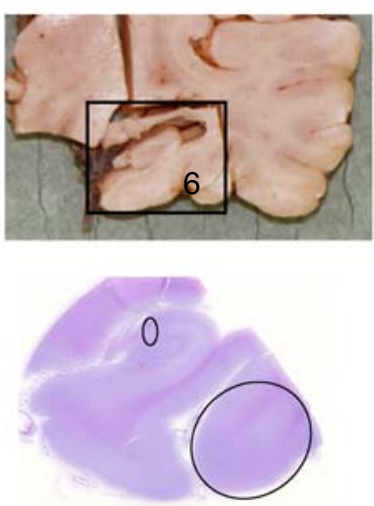

6. Hippocampus

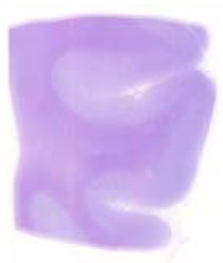

9. Frontal cortex

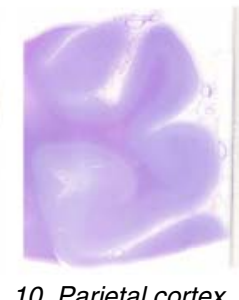

10. Parietal cortex

lesions in various extent. Thus, cases with all stages from mild to severe involvement with $\alpha \mathrm{S}$-IR lesions were available for assessment. A total of five sets of 7 - $\mu$ m-thick sections were produced from 10 brain areas of the 31 cases. The demographics of the included material are shown in Table 2.

\section{Immunohistochemistry}

Five sets of the ten sampled sections were manually stained by applying IHC methodology. In brief, after rehydration, the sections were autoclaved in citrate buffer and pretreated with $80 \%$ formic acid for $5 \mathrm{~min}$. Subsequently, the sections were incubated overnight at $4^{\circ} \mathrm{C}$ with a monoclonal primary antibody directed against $\alpha \mathrm{S}$ (Novocastra/

NCL-ASYN, clone KM51, dilution 1:1,000). The reaction product was visualized using the Zymed Lab-SA detection system (Zymed, San Fransisco, CA, USA) with the use of Biosource Romulin AEC as the chromogen (Biocare Medical, Walnut Creek, CA, USA).

Reference assessment and construction of assessment instructions

The members of the reference group (I.A., P.I., H.K., J.I., J.B., S.G.) simultaneously assessed all the cases using a multi-headed microscope (Table 2). The reference group assigned each case to Braak's stage and McKeith's type according to the original publications from 2003 and 2005 $[5,20]$. In addition, the regularity of the caudal to rostral 
Table 2 Demographics of the cases included and the stage of $\alpha$-synuclein pathology obtained by the reference group following original instructions

\begin{tabular}{|c|c|c|c|c|c|c|c|c|}
\hline \multirow[t]{2}{*}{ Case } & \multirow[t]{2}{*}{ Gender } & \multirow{2}{*}{$\begin{array}{l}\text { Age at } \\
\text { death }\end{array}$} & \multirow{2}{*}{$\begin{array}{l}\text { Cognitive } \\
\text { impairment }\end{array}$} & \multirow{2}{*}{$\begin{array}{l}\text { Brain } \\
\text { weight }\end{array}$} & \multirow{2}{*}{$\begin{array}{l}\text { AD related Braak } \\
\text { stage [7] }\end{array}$} & \multicolumn{3}{|c|}{$\alpha$-synuclein immunoreactive pathology } \\
\hline & & & & & & $\begin{array}{l}\text { Braak } \\
\text { stage [5] }\end{array}$ & $\begin{array}{l}\text { McKeith } \\
\text { type [20] }\end{array}$ & $\begin{array}{l}\text { Amygdala- } \\
\text { predominant }\end{array}$ \\
\hline 1 & Female & 70 & & 1,290 & 2 & 1 & 1 & \\
\hline 2 & Male & 75 & Yes & 1,500 & 1 & 2 & 1 & \\
\hline 3 & Male & 57 & & 1,280 & 0 & 3 & 1 & \\
\hline 4 & Male & 70 & & 1,535 & 1 & $3^{\mathrm{a}}$ & 1 & \\
\hline 5 & Male & 76 & & 1,680 & 1 & 3 & 1 & \\
\hline 6 & Male & 83 & & 1,210 & 1 & 3 & 1 & \\
\hline 7 & Male & 62 & & 1,505 & 0 & 4 & 1 & \\
\hline 8 & Female & 71 & Yes & 1,000 & 2 & 4 & 1 & \\
\hline 9 & Female & 73 & & 1,440 & 2 & 4 & 1 & \\
\hline 10 & Female & 74 & & 1,260 & 2 & $4^{\mathrm{a}}$ & 1 & \\
\hline 11 & Female & 77 & & 1,345 & 1 & $4^{\mathrm{a}}$ & 1 & \\
\hline 12 & Female & 78 & & 1,480 & 2 & $4^{\mathrm{a}}$ & 1 & \\
\hline 13 & Female & 80 & & 1,560 & 0 & 4 & 1 & \\
\hline 14 & Male & 78 & & 1,450 & 1 & 4 & 2 & $\mathrm{Yes}^{\mathrm{b}}$ \\
\hline 15 & Male & 83 & Yes & 1,395 & 2 & 4 & 2 & \\
\hline 16 & Male & 63 & & 1,535 & 0 & $5^{\mathrm{a}}$ & 2 & \\
\hline 17 & Female & 74 & Yes & 1,255 & 2 & $5^{\mathrm{a}}$ & 2 & $\mathrm{Yes}^{\mathrm{b}}$ \\
\hline 18 & Male & 80 & & 1,300 & 4 & $5^{\mathrm{a}}$ & 2 & $\mathrm{Yes}^{\mathrm{b}}$ \\
\hline 19 & Male & 76 & & 1,420 & 1 & 5 & 2 & \\
\hline 20 & Male & 78 & & 1,600 & 2 & 5 & 2 & $\mathrm{Yes}^{\mathrm{b}}$ \\
\hline 21 & Male & 68 & & 1,275 & 0 & 6 & 2 & \\
\hline 22 & Female & 74 & Yes & 1,305 & 6 & 6 & 2 & $\mathrm{Yes}^{\mathrm{b}}$ \\
\hline 23 & Female & 79 & Yes & 1,090 & 6 & $6^{\mathrm{a}}$ & 2 & $\mathrm{Yes}^{\mathrm{b}}$ \\
\hline 24 & Male & 89 & & 1,135 & 2 & $6^{\mathrm{a}}$ & 2 & \\
\hline 25 & Male & 77 & & 1,480 & 0 & 6 & 3 & \\
\hline 26 & Male & 67 & & 1,490 & 2 & 6 & 3 & \\
\hline 27 & Male & 70 & Yes & 1,345 & 1 & 6 & 3 & \\
\hline 28 & Male & 72 & & 1,460 & 1 & 6 & 3 & \\
\hline 29 & Male & 73 & & 1,490 & 0 & 6 & 3 & \\
\hline 30 & Male & 74 & Yes & 1,485 & 2 & 6 & 3 & \\
\hline 31 & Male & 83 & Yes & 1,325 & 3 & 6 & 3 & \\
\hline
\end{tabular}

$A D$ Alzheimer's disease related pathology, i.e. Braak stage of hyperphosphorylated-tau immunoreactive neurofibrillary pathology

a The caudal to rostral progression as given in Table 1a was not regular, i.e. the case is atypical regarding the distribution of pathology

b Amygdala predominant type, i.e. the pathology is most severe in amygdala

distribution of pathology was assessed and discrepant cases were identified as atypical (Table 2). When a prominent involvement of the amygdala was seen (e.g. amygdaloid $\alpha \mathrm{S}$ pathology present in excess compared to brainstem involvement), the case was classified as being of amygdalapredominant type.

Assessment instructions were written by two members of the reference group (I.A., P.I.). The instructions included a detailed description of the samples (Fig. 2), photographs of the pathology to be assessed (Figs. 3, 4), general instructions regarding assessment (Table 3) and detailed tabulated guidelines on the staging and typing (Table 1). Participants were encouraged to read the original publications.

Inter-observer assessment

Twenty-two participants assessed and staged each case as instructed. The results were recorded on the assessment sheets (Table 4) which were collected in the coordinating 

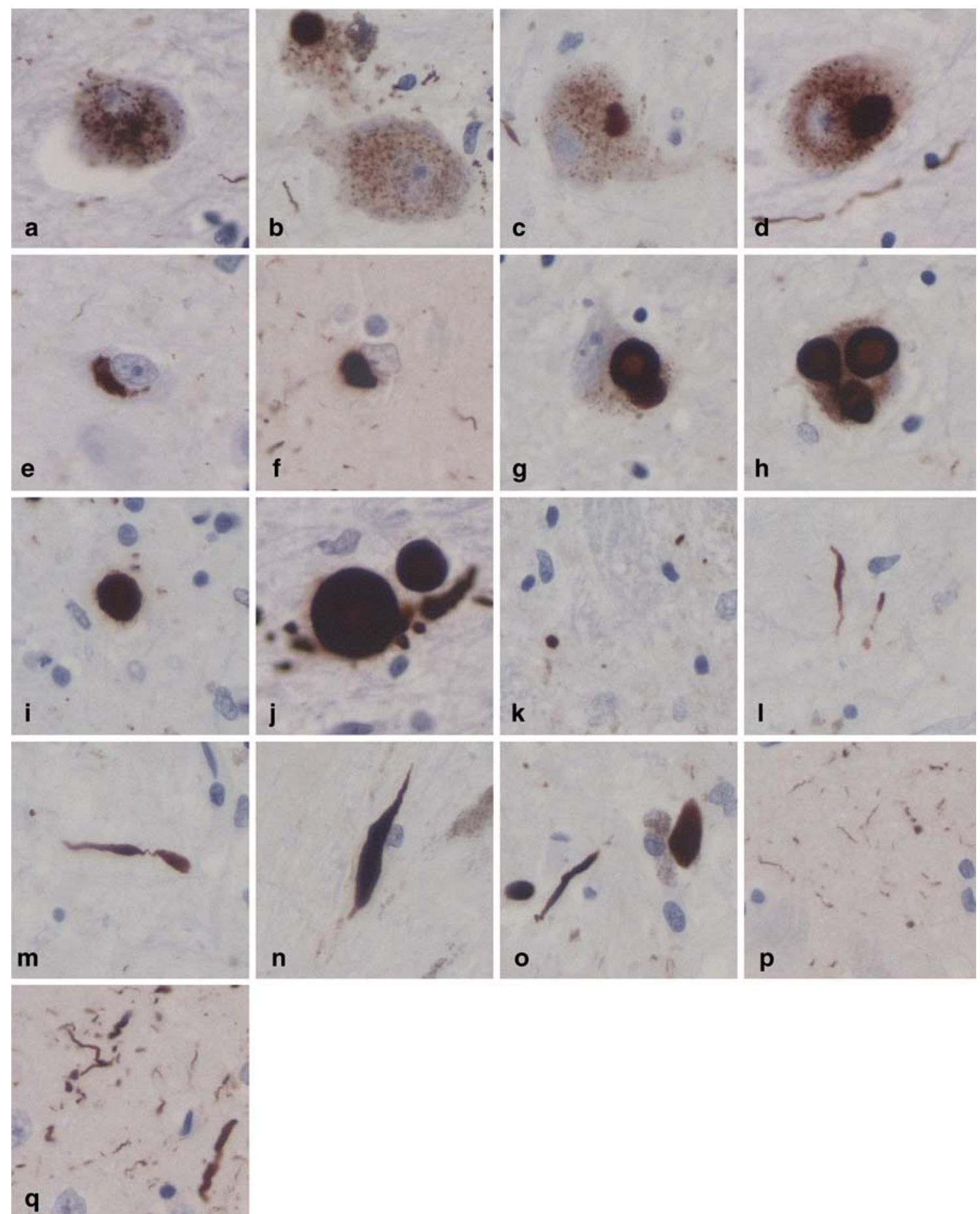

Fig. $3 \alpha$-synuclein immunoreactive pathological structures $\mathbf{a}-\mathbf{d}$ grain like cytoplasmic, $\mathbf{b}-\mathbf{h}$ intracytoplasmic Lewy body like inclusions, $\mathbf{i}, \mathbf{j}$ extracellular Lewy body like inclusions and $\mathbf{k}-\mathbf{q} \alpha$-synuclein immunolabelled neurites

centre where the data were integrated for analysis. These assessment sheets included information on whether or not the participant had identified the target neuroanatomical regions, whether or not $\alpha \mathrm{S}$ pathology was seen, an assessment of LBs and LNs and the designated stage and type of each case. In addition, each participant stated whether the distribution of pathology seemed to progress as expected (i.e. typical vs. atypical case) and whether amygdala-predominant synucleinopathy was observed.

Consensus meeting and joint assessment

Following the phase of individual assessment, the group convened a meeting to jointly assess all IHC labelled 
Fig. 4 Density of labeling assessed on a four step scale from 0 to 3 in $d m V$ dorsal motor nucleus of vagus; $L C$ locus ceruleus; $S N$ substantia nigra, pars compacta; $A C$ amygdala; Ento entorhinal cortex, cortex and CA2 region of Ammon's horn. Scale 0 represents no pathological aggregates, 1 some, 2 moderate and 3 numerous pathological aggregates. The figures illustrate the progression of the lesions from mild to severe seen in $\times 100(\mathrm{CA} 2 \times 200)$

magnifications
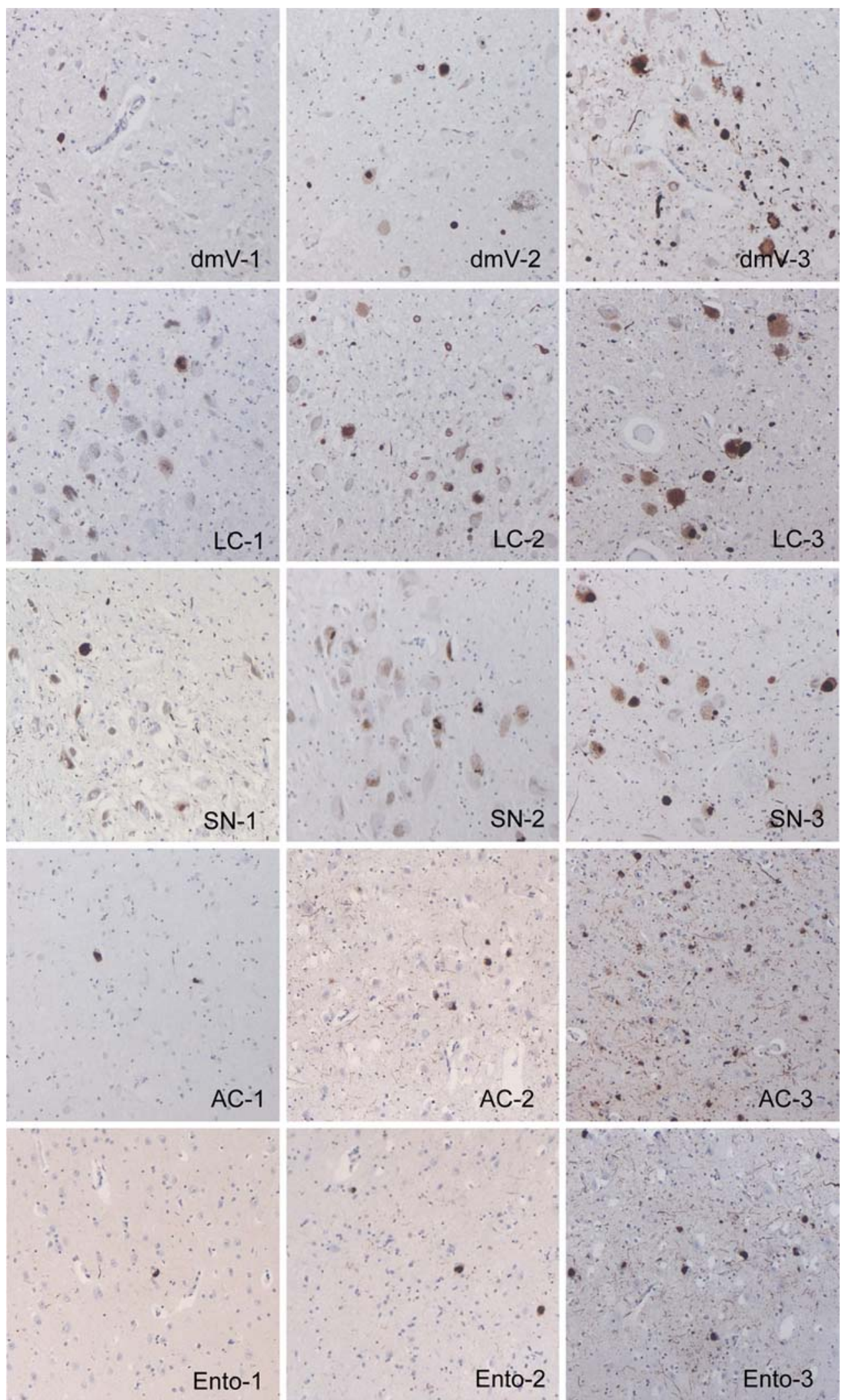

sections around a multi-headed microscope. The diagnostic features of each stage were discussed. While assessing the stained sections under the multi-headed microscope, the actual observations were compared with the data recorded in the assessment sheets. Inconsistencies in these observations were discussed and pitfalls were sought. 
Fig. 4 continued
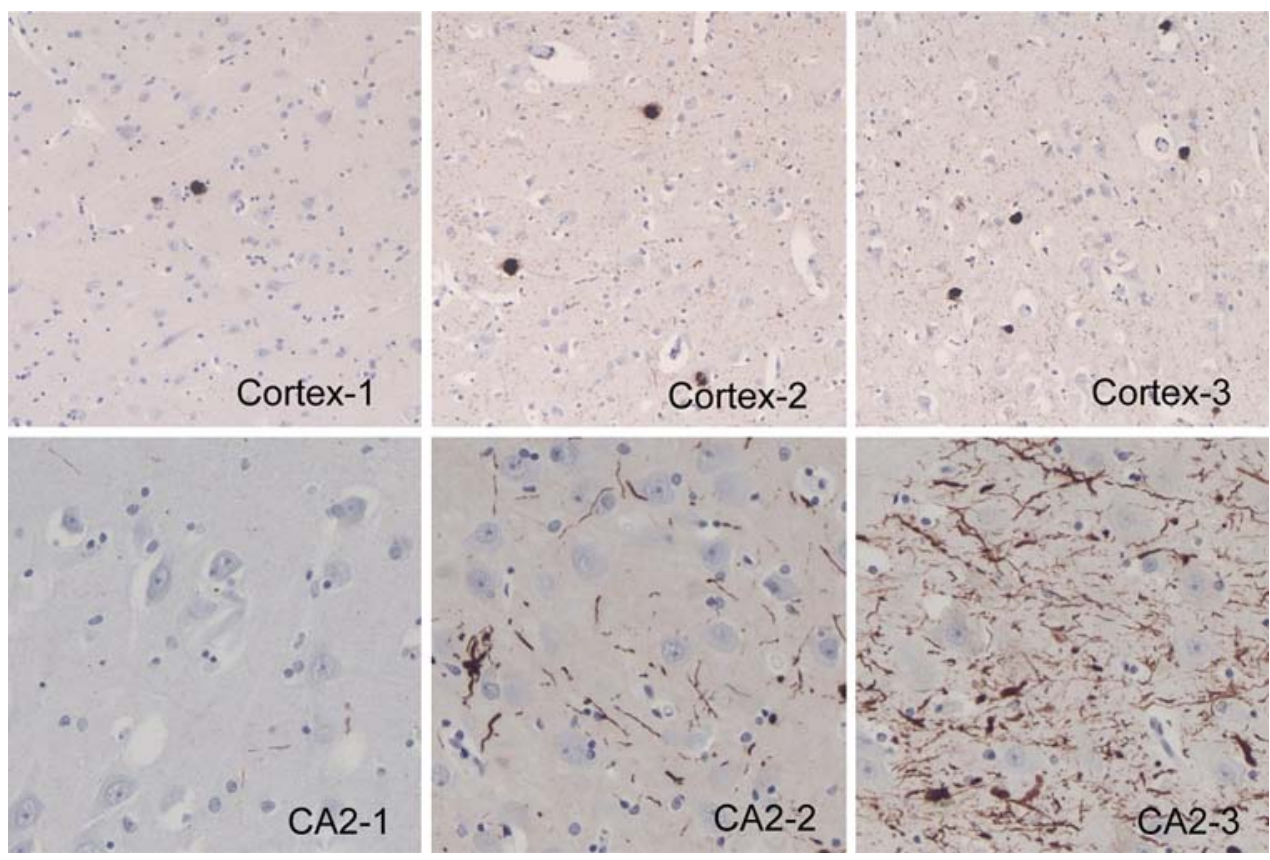

Table 3 Instructions for the assessment of $\alpha$-synuclein $(\alpha S)$ immunoreactive (IR) Lewy body (LB) related pathology

1. State for each sample (Fig. 2) whether or not (yes/no) the assessable region is included in the section

2. State for each assessable and identified region whether or not (yes/no) $\alpha \mathrm{S}$-IR pathological structures are seen. $\alpha \mathrm{S}+$ covers intracytoplasmic grains, inclusions, extracellular inclusions, aggregates, neurites, threads (Fig. 3)

3. State for the selected regions whether or not (yes/no) $\alpha$ S-IR LB-like lesions are seen. The rounded LB like inclusions may be located in a neuron or may be extracellular (Fig. 3b-j)

4. State for the selected regions whether or not (yes/no) aS-IR neurites are seen. LB related neurite or neuropil thread is a tiny rounded, fusiform or strip like IHC/ $\alpha \mathrm{S}+$ structure in the neuropil (Fig. $3 \mathrm{k}-\mathrm{q}$ )

5. Assess the density of $\alpha \mathrm{S}+$ in each anatomical region. It is recommended but not required to use the magnification $\times 100$ (Fig. 4 )

0 . no $\alpha S-I R$ in the area of interest

1. sparse/mild $\alpha$ S- IR in x100 magnification only occasional $\alpha$ S-IR structures are seen and in cortex only a few LB-like inclusions are seen in the whole gyrus

2. moderate $\alpha \mathrm{S}$-IR in x100 magnification scattered $\alpha \mathrm{S}$-IR structures are seen and in cortex patchy/intervening areas lack LB-like inclusions but neurites might be widespread

3. severe $\alpha$ S-IR in x100 magnification numerous $\alpha$ S-IR structures are seen and in cortex LB-like inclusions are relatively uniformly distributed with numerous neurites

6. Assign a Braak stage if possible [5]. The progress from stage 1 to stage 6 is not stepwise but instead is continuous, so select a stage that is most representative

7. Assign a McKeith type if possible [20]. The progress from brainstem predominant to neocortical is not stepwise but instead is continuous thereby select a stage that is most descriptive

8. In some cases the distribution of the pathology might not be as strict as delineated by Braak and colleagues in 2003 or McKeith and colleagues from in 2005 [5, 20]. Please indicate as requested in the assessment sheet whether the distribution of the pathology in caudal to rostral direction is regular i.e. typical, or not i.e. atypical

9. In some cases the distribution of the pathology might not be as strict as delineated by Braak and colleagues in 2003 or McKeith and colleagues from in 2005 [5, 20]. In some cases an amygdala predominant pattern might be seen i.e. the pathology is most severe in amygdaloid complex and less pronounced in brainstem areas. State whether the assessed case should be considered as an amygdala predominant one

Re-examining the data found in the assessment sheets

Detailed data found in the original assessment sheets were re-examined and a Braak stage and McKeith type was assigned following a new modification of original protocols designed by the members of BNE during the consensus meeting. In addition, the data in the original assessments sheets were used to assign a Braak stage as described by Müller and colleagues in 2005 (Table 1b) and a McKeith type as described by Leverenz and colleagues in 2008 


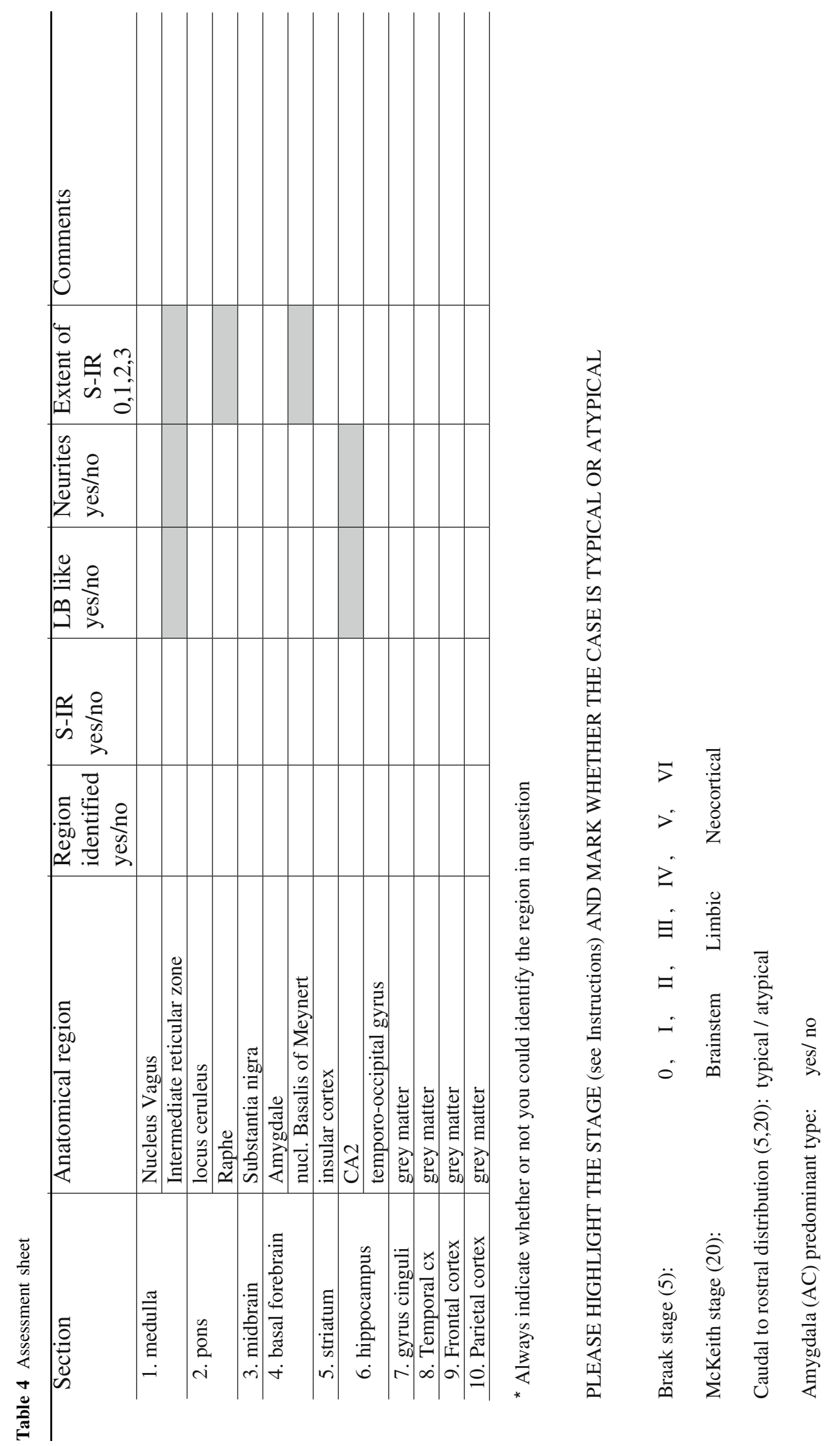


(Table 1d) [18, 21]. Regarding the assignment of Braak stage as described by Müller and colleagues, in the place of the mesocortical transentorhinal cortex the mesocortical temporo-occipital cortex was included since this region is affected to an equivalent extent. The above adjustments did not require re-assessment of slides as all of the required data was readily available in the original assessment sheets.

\section{Statistical analysis and photography}

The statistical analyses were conducted with SPSS 16 for Windows. The agreement in the assessments was estimated applying the nonparametric Wilcoxon rank-sum test. In addition, the value of absolute agreement (\%) was calculated, that is, the proportion of equal assessments. Digital images were taken using a Leica DM4000 B microscope equipped with a Leica DFC 320 digital camera.

\section{Results}

The results from the individual assessments (i.e. prior to the consensus meeting) are summarized in Tables 5 and 6 . All assessors detected $\alpha \mathrm{S}$ pathology in all cases and the agreement of the Braak stage ranged from 32 to $100 \%$ (Table 5) significantly differing in 24 out of 31 cases. All the assessors were in agreement on the assigned stage in only 4 out of 31 cases (all cases with Braak stage 6). In 30 out of 31 cases, most of the assessors agreed with the reference group (except \#9). The overall agreement was $65 \%$ and agreement was highest in stages 1 (95\%) and 6 (79\%). In $27 \%$ of assessments (24 cases), a lower and in $24 \%$ (17 cases) a higher stage was given when compared to the reference assessment. There was only a $55 \%$ agreement between the assessments when only the twelve cases that were considered by the reference group as being atypical in their caudal to rostral distribution of $\alpha \mathrm{S}$ pathology or those assessed to be of the amygdala-predominant type were included. Agreement increased to $70 \%$ only when the 19 cases with a typical distribution of pathology were included. Out of these 19 assessments, 12 differed significantly $(P<0.05)$.

Agreement between assessments of McKeith type synucleinopathy ranged from 45 to $100 \%$ significantly differing in 11 out of 31 cases (Table 6). All participants agreed that a case corresponded to the same McKeith type in only five cases. However, in all cases, the majority of assessors agreed with the reference group. The overall agreement was $80 \%$, being highest in brainstem type $(86 \%)$ followed by neocortical type $(82 \%)$. Nine out of 31 cases (29\%) were assigned by some assessors as being of brainstem, by others they were believed to be limbic and by yet others as being of neocortical type. There was $73 \%$ agreement between the assessments when the six cases considered to be of the amygdala-predominant type were included and the agreement increased from 73 to $83 \%$, if only the 25 remaining cases were included. Out of these 25 assessments, 8 differed significantly $(P<0.05)$.

There was extensive variation in the agreement regarding assessment of typical versus atypical caudal to rostral propagation. Following the strategy delineated by Braak and colleagues, most of the individual assessments agreed with the reference group in six out of the nine atypical cases (\# 11,12,17,18, 23, 24). Overall agreement about typical versus atypical distribution of pathology exceeded $75 \%$ in only 12 out of 31 cases. In only 11 cases did all assessors agree that the $\alpha \mathrm{S}$ pathology displayed a typical distribution pattern.

According to the reference group, six cases displayed an amygdala-predominant $\alpha \mathrm{S}$ pathology. The majority of the individual assessments were in agreement in five of these cases (\# 14, 17, 18, 22 and 23). In all six cases, all individual assessments noted the substantial $\alpha \mathrm{S}$ pathology in amygdala. In one other case (\#20) in contrast to the reference group, some observers had also observed substantial pathology in the brainstem (Table 7). In all of the remaining cases with pathology in the amygdala, the severity of $\alpha \mathrm{S}$ pathology was proportionate to that seen in the midbrain/brainstem. Nevertheless, 12 of these cases were considered by some observers to be of the amygdalapredominant type.

Most of the assessors participated in the consensus meeting where there was a joint assessment of all cases. Issues such as whether or not a case fulfilled the staging requirements (i.e. typical vs. atypical case or whether or not a case should be labelled as an amygdala-predominant type) were debated. It became evident that the primary obstacle was not in microscopic assessment but rather in the assignment of the Braak stage and the McKeith type $[5,20]$. With respect to the Braak stage, problems were encountered when all regions were not affected with $\alpha \mathrm{S}$ pathology. The major obstacle in the assignment of McKeith type was the overlap of $\alpha \mathrm{S}$-IR pathology between the subtypes. This arose from the lack of clarity in the difference between brainstem and the limbic categories or limbic and neocortical categories. After these discussions, a new modification of the original assessment protocols referred to as the 'BNE protocol' was formulated to increase the agreement between the assessments (Fig. 5). The issue of a threshold level of $\alpha \mathrm{S}$ pathology was widely debated, e.g. does a single $\mathrm{LN}$ in an anatomical region indicate that the region is involved and taken into consideration in the modified protocol (Fig. 5). In the newly designed BNE protocol, 13 anatomical regions repeatedly identified and found in 9 sampled blocks were included. Thus, each Braak stage and each McKeith type were 
Table 5 Agreement between the reference group and among 22 assessors in Braak's staging [5]

\begin{tabular}{|c|c|c|c|c|c|c|c|c|c|c|c|c|c|}
\hline \multirow[t]{2}{*}{ Case } & \multirow[t]{2}{*}{ Reference group } & \multicolumn{6}{|c|}{$\begin{array}{l}\text { Braak stage } \\
\text { Stage given by the } 22 \text { participating observers }\end{array}$} & \multicolumn{3}{|c|}{ Absolute agreement in percent } & \multicolumn{3}{|c|}{ Wilcoxon rank-sum test } \\
\hline & & 1 & 2 & 3 & 4 & 5 & 6 & Single case & One stage & Overall & Single case & One stage & Overall \\
\hline 1 & 1 & 21 & 1 & & & & & 95 & 95 & & & & \\
\hline 2 & 2 & 8 & 14 & & & & & 64 & 64 & & $*$ & $*$ & \\
\hline 3 & 3 & 1 & 7 & 11 & 3 & & & 50 & & & $*$ & & \\
\hline 4 & $3^{\mathrm{a}}$ & 5 & & 17 & & & & 77 & 63 & & $*$ & & \\
\hline 5 & 3 & & & 13 & 8 & 1 & & 59 & & & $*$ & $*$ & \\
\hline 6 & 3 & 3 & 4 & 14 & & 1 & & 64 & & & $*$ & & \\
\hline 7 & 4 & & & 8 & 13 & 1 & & 59 & & & $*$ & & \\
\hline 8 & 4 & & & 3 & 17 & 2 & & 77 & & & $*$ & & \\
\hline 9 & 4 & & & 5 & 8 & 7 & 2 & 32 & & & $*$ & & \\
\hline 10 & $4^{\mathrm{a}}$ & & & 8 & 10 & 4 & & 45 & 55 & & $*$ & & \\
\hline 11 & $4^{\mathrm{a}}$ & & 5 & 7 & 10 & & & 45 & & & $*$ & & \\
\hline 12 & $4^{\mathrm{a}}$ & & & 5 & 10 & 6 & 1 & 45 & & & $*$ & $*$ & \\
\hline 13 & 4 & & & 1 & 19 & 2 & & 86 & & 65 & & & \\
\hline 14 & $4^{\mathrm{b}}$ & & & & 13 & 4 & 5 & 59 & & & $*$ & & \\
\hline 15 & 4 & & & & 10 & 9 & 3 & 45 & & & $*$ & & \\
\hline 16 & $5^{\mathrm{a}}$ & & & & 3 & 10 & 9 & 45 & & & $*$ & & \\
\hline 17 & $5^{\mathrm{a}, \mathrm{b}}$ & & & & 7 & 11 & 4 & 50 & & & $*$ & & $*$ \\
\hline 18 & $5^{\mathrm{a}, \mathrm{b}}$ & & & & 7 & 9 & 6 & 41 & 52 & & $*$ & $*$ & \\
\hline 19 & 5 & & & & 3 & 12 & 7 & 55 & & & $*$ & & \\
\hline 20 & $5^{\mathrm{b}}$ & & & & 1 & 15 & 6 & 68 & & & $*$ & & \\
\hline 21 & 6 & & & 1 & 7 & 4 & 10 & 45 & & & $*$ & & \\
\hline 22 & $6^{\mathrm{b}}$ & & & & 4 & 5 & 13 & 59 & & & $*$ & & \\
\hline 23 & $6^{\mathrm{a}, \mathrm{b}}$ & & & & & 7 & 15 & 68 & & & $*$ & & \\
\hline 24 & $6^{\mathrm{a}}$ & & & & 6 & 4 & 12 & 55 & & & $*$ & & \\
\hline 25 & 6 & & & & 2 & 3 & 17 & 77 & 79 & & $*$ & & \\
\hline 26 & 6 & & & & & & 22 & 100 & & & & $*$ & \\
\hline 27 & 6 & & & & & & 22 & 100 & & & & & \\
\hline 28 & 6 & & & & & 3 & 19 & 86 & & & & & \\
\hline 29 & 6 & & & & 3 & 3 & 16 & 73 & & & $*$ & & \\
\hline 30 & 6 & & & & & & 22 & 100 & & & & & \\
\hline 31 & 6 & & & & & & 22 & 100 & & & & & \\
\hline
\end{tabular}

* $P<0.05$ by means of Wilcoxon rank-sum test are given for a single case, on the level of a Braak stage and overall including all 31 cases a Atypical distribution

b Amygdala-predominant type as determined by the reference group. Inter-rater agreement given in bold. Absolute agreement and significant difference

represented by at least two neuroanatomical regions to ensure better reproducibility in the assessment results. Furthermore, the lesions requested to be seen in the region of interest were defined as being LBs or LNs or both. No counting of IR lesions was required and only in the case of the amygdala-predominant category was an arbitrary assessment of the extent of pathology required (Fig. 5).

Table 8 summarises the assessment results and the rate of inter-observer agreement while following the BNE protocol compared to the earlier modifications of the Braak's staging and McKeith's typing of $\alpha \mathrm{S}$ pathology [18, 21].
While following the BNE-protocol, the Braak stage differed in four cases when compared to the original reference assessment (case 5 Braak stage $3 \rightarrow 4$; case 9, 12 and 14 Braak stage $4 \rightarrow 5 / 6$ ). The original McKeith type was altered in 13 cases (cases 5, 7-13 McKeith brainstem $\rightarrow$ limbic; cases16, 21, 23 and 24 McKeith limbic $\rightarrow$ neocortical). Using the BNE-protocol, the overall agreement regarding the Braak stage increased from 65 to $83 \%$ and with respect to the McKeith type from 81 to $84 \%$. It is noteworthy that while applying the BNE protocols for Braak staging and McKeith typing, the number of 
Table 6 Agreement among 22 assessors in McKeith's typing [20]

\begin{tabular}{|c|c|c|c|c|c|c|c|c|c|c|c|}
\hline \multirow[t]{2}{*}{ Case } & \multirow[t]{2}{*}{ Reference group } & \multicolumn{4}{|c|}{$\begin{array}{l}\text { McKeith type } \\
\text { Type given by the } 22 \text { participants }\end{array}$} & \multicolumn{3}{|c|}{ Absolute agreement in percent } & \multicolumn{3}{|c|}{ Wilcoxon-rank-sum test $* p<0.05$} \\
\hline & & 0 & Brainstem & Limbic & Neocortical & Single case & One type & Overall & Single case & One type & Over all \\
\hline 1 & Brainstem & & 22 & & & 100 & & & & & \\
\hline 2 & Brainstem & & 22 & & & 100 & & & & & \\
\hline 3 & Brainstem & & 21 & 1 & & 95 & & & & & \\
\hline 4 & Brainstem & & 22 & & & 100 & & & & & \\
\hline 5 & Brainstem & & 20 & 2 & & 91 & & & & & \\
\hline 6 & Brainstem & 2 & 20 & & & 91 & & & & & \\
\hline 7 & Brainstem & & 19 & 3 & & 86 & 85 & & & & \\
\hline 8 & Brainstem & & 15 & 7 & & 68 & & & $*$ & & \\
\hline 9 & Brainstem & & 13 & 8 & 1 & 59 & & & $*$ & & \\
\hline 10 & Brainstem & & 18 & 4 & & 82 & & & & & \\
\hline 11 & Brainstem & & 20 & 2 & & 91 & & & & & \\
\hline 12 & Brainstem & & 15 & 7 & & 68 & & & $*$ & & \\
\hline 13 & Brainstem & & 16 & 6 & & 73 & & & $*$ & & \\
\hline 14 & $\operatorname{Limbic}^{\mathrm{a}}$ & & 3 & 16 & 3 & 86 & & & $*$ & & \\
\hline 15 & Limbic & & 3 & 19 & & 86 & & 81 & & & $*$ \\
\hline 16 & Limbic & & & 19 & 3 & 86 & & & & & \\
\hline 17 & $\operatorname{Limbic}^{\mathrm{a}}$ & & 4 & 18 & & 82 & & & & & \\
\hline 18 & $\operatorname{Limbic}^{\mathrm{a}}$ & & 2 & 18 & 2 & 86 & 73 & & & $*$ & \\
\hline 19 & Limbic & & & 21 & 1 & 95 & & & & & \\
\hline 20 & $\operatorname{Limbic}^{\mathrm{a}}$ & & 1 & 19 & 2 & 86 & & & & & \\
\hline 21 & Limbic & & 7 & 12 & 3 & 55 & & & $*$ & & \\
\hline 22 & $\operatorname{Limbic}^{\mathrm{a}}$ & & 3 & 10 & 9 & 45 & & & $*$ & & \\
\hline 23 & $\operatorname{Limbic}^{\mathrm{a}}$ & & & 11 & 11 & 50 & & & $*$ & & \\
\hline 24 & Limbic & & 3 & 14 & 5 & 64 & & & $*$ & & \\
\hline 25 & Neocortical & & & 7 & 15 & 68 & & & $*$ & & \\
\hline 26 & Neocortical & & & & 22 & 100 & & & & & \\
\hline 27 & Neocortical & & & 1 & 21 & 95 & & & & & \\
\hline 28 & Neocortical & & 1 & 8 & 13 & 59 & 82 & & $*$ & & \\
\hline 29 & Neocortical & & 4 & 4 & 14 & 64 & & & $*$ & & \\
\hline 30 & Neocortical & & & & 22 & 100 & & & & & \\
\hline 31 & Neocortical & & & 2 & 20 & 91 & & & & & \\
\hline
\end{tabular}

* $P<0.05$ by means of Wilcoxon rank-sum test are given for a single case, on the level of a McKeith category and overall including all 31 cases ${ }^{a}$ Amygdala predominant type as determined by the reference group. Inter-rater agreement given in bold. Absolute agreement and significant difference

cases with significantly differing $(P<0.05)$ assessments dropped from 17 to 10 and from 12 to 10 cases, respectively.

Rather similar agreement was obtained when applying the strategy proposed by Müller and colleagues [21], assessing $\alpha \mathrm{S}$ in fewer brain regions. It is noteworthy, however, that the original assessment results were altered in as many as 12 cases and some of these alterations were substantial (case 17 stage $5 \rightarrow 3$ and case 21 stage $6 \rightarrow 3$ ). The strategy proposed by Leverenz and colleagues [18] (i.e. assessing fewer brain regions and taking into account also the amygdala-predominant type) largely followed the pattern obtained when applying the BNE protocol.

There was one significant difference when comparing the BNE protocol with the previous modifications of the widely accepted categorization strategies. If one utilized the newly designed BNE protocol, then the inter-observer agreement was $70 \%$ or more in most cases (Table 8 ). The assessment differed significantly $(P<0.05)$ in 14 out of 31 cases when applying the strategy proposed by Leverenz, when compared with 10 cases when following the protocol designed by BNE. 
Table 7 Mean \pm standard error (SE) of the semiquantitative assessment of $\alpha$-synuclein $(\alpha \mathrm{S})$ immunoreactive pathology by 22 observers

\begin{tabular}{llllll}
\hline Case & $\mathrm{dmV}$ mean $\pm \mathrm{SE}$ & $\mathrm{SN}$ mean $\pm \mathrm{SE}$ & AC mean $\pm \mathrm{SE}$ & $\mathrm{GC}$ mean $\pm \mathrm{SE}$ & $\mathrm{P}$ cx mean $\pm \mathrm{SE}$ \\
\hline 14 & $2.22 \pm 0.09$ & $2.17 \pm 0.17$ & $3.00 \pm 0.13$ & $1.57 \pm 0.32$ & $0.39 \pm 0.22$ \\
17 & $1.74 \pm 0.14$ & $1.74 \pm 0.14$ & $3.00 \pm 0.20$ & $1.96 \pm 0.31$ & $0.13 \pm 0.13$ \\
18 & $1.57 \pm 0.18$ & $1.83 \pm 0.12$ & $2.78 \pm 0.11$ & $2.39 \pm 0.27$ & $0.26 \pm 0.18$ \\
20 & $2.48 \pm 0.11$ & $3.17 \pm 0.12$ & $3.65 \pm 0.12$ & $2.74 \pm 0.18$ & 0 \\
22 & $1.96 \pm 0.10$ & $2.35 \pm 0.10$ & $3.96 \pm 0.43$ & $2.35 \pm 0.26$ & $0.13 \pm 0.13$ \\
23 & $1.22 \pm 0.21$ & $1.30 \pm 0.20$ & $4.00 \pm 0.00$ & $3.26 \pm 0.18$ & $0.65 \pm 0.26$ \\
$T$ test & 0.000 & 0.000 & & 0.000 & 0.000
\end{tabular}

Six cases with amygdala-predominant pathology as assessed by the reference group listed. The extent of pathology in various neuroanatomical regions differed significantly ( $T$ test) when compared with the extent seen in the amygdaloid nucleus

Abbreviations of neuroanatomical regions: $d m V$ dorsal motor nucleus of vagus, $S N$ substantia nigra, $A C$ amygdaloid nucleus, $G C$ gyrus cinguli, $P c x$ parietal cortex

\begin{tabular}{|c|c|c|c|c|c|c|c|c|c|c|c|c|c|}
\hline Sampled & \multicolumn{2}{|c|}{ Medulla } & \multicolumn{2}{|c|}{ Pons } & Midbrain & \multicolumn{2}{|c|}{ Basal Forebrain } & \multicolumn{2}{|c|}{ Hippocampus } & \multirow{2}{*}{$\begin{array}{c}\begin{array}{c}\text { Gyrus } \\
\text { cinguli }\end{array} \\
\begin{array}{c}\text { grey } \\
\text { matter }\end{array}\end{array}$} & \multirow{2}{*}{$\begin{array}{c}\begin{array}{c}\text { Temporal } \\
\text { cortex }\end{array} \\
\text { grey } \\
\text { matter }\end{array}$} & \multirow{2}{*}{$\begin{array}{c}\begin{array}{c}\text { Frontal } \\
\text { cortex }\end{array} \\
\begin{array}{c}\text { grey } \\
\text { matter }\end{array}\end{array}$} & \multirow{2}{*}{$\begin{array}{c}\begin{array}{c}\text { Parietal } \\
\text { cortex }\end{array} \\
\begin{array}{c}\text { grey } \\
\text { matter }\end{array}\end{array}$} \\
\hline $\begin{array}{l}\text { Anatomical } \\
\text { region }\end{array}$ & $\mathrm{dmV}$ & irx & LC & $\mathrm{R}$ & SN & $\mathrm{nbM}$ & $\mathrm{AC}$ & $\mathrm{CA} 2$ & TOcx & & & & \\
\hline Braak stage & 1 & 1 & 2 & 2 & 3 & 3 & 4 & 3 & 4 & 5 & 5 & 6 & 6 \\
\hline $\begin{array}{l}\text { McKeith } \\
\text { type }\end{array}$ & \multicolumn{5}{|c|}{ BRAINSTEM } & \multicolumn{6}{|c|}{ LIMBIC } & \multicolumn{2}{|c|}{ NEOCORTICAL } \\
\hline $\begin{array}{l}\text { Amygdala } \\
\text { predominant }\end{array}$ & & & & & & & $\begin{array}{c}\mathrm{AC} \\
\text { predominant }\end{array}$ & & & & & & \\
\hline $\begin{array}{l}\text { Lesion type } \\
\text { requested }\end{array}$ & \multicolumn{6}{|c|}{ LBs and / or LNs } & LBs & LNs & \multicolumn{5}{|c|}{ LBs } \\
\hline
\end{tabular}

Fig. 5 BrainNet Europe protocol, i.e. assignment of the Braak stage and McKeith type of $\alpha$-synuclein $(\alpha S)$ immunoreactive (IR) Lewy body (LB) disease related pathology as proposed by BrainNet Europe consortium. $d m V$ Dorsal motor nucleus of vagus, irx intermediate reticular zone, $L C$ locus coeruleus, $R$ raphe, $S N$ substantia nigra, $n b M$ nucleus basalis of Meynert, $A C$ amygdala, $C A 2$ cornu Ammonis of hippocampus, region 2 TOcx temporo-occipital cortex. $L N$ Lewy neurites. Two to three regions represent each Braak stage. For a Braak stage only one of the required regions needs to be affected with the required (LB or LN) $\alpha$ S-IR pathology. Note, if a case does not fulfil sequentially all Braak stages, it is designated as an IF case, i.e. staging

In the original assessment, six cases (\# 11,12,17,18, 23, 24) were considered by most assessors to be atypical with respect to the caudal to rostral propagation of pathology. The data recorded in the assessment sheets showed that five cases (\# 4, 17,18, 23, 24) did not fulfil the anatomical sequence of Braak's staging in most assessments and these cases were thus designated as "staging criteria incompletely fulfilled" as recommended by the BNE protocol.

\section{Discussion}

Remarkably good agreement, over $80 \%$, was achieved in this study when 22 observers assessed 31 cases with $\alpha \mathrm{S}$ pathology. It is noteworthy that this high rate of agreement criteria incompletely fulfilled. For the McKeith brainstem type, one of the obligatory brainstem regions (medulla, pons, midbrain) has to be affected with LB and or LN. Only one of the two regions in Limbic or Neocortical type needs to be affected with the required (LB or LN) pathology to merit classification to this category. In Amygdala predominant type, the $\alpha \mathrm{S}$-IR LBs are either noted only in the AC or they are seen in excess in $\mathrm{AC}$ when compared to the brainstem regions. If occasional $\alpha \mathrm{S}$-IR LNs are seen in AC or in cortical regions without LBs, the case is assigned as a " + " case, i.e. a Braak stage $3+$ or a McKeith brainstem + , when the case displays LBs and/or LNs up till midbrain but in addition LNs are seen in neocortical areas

required modification of both of the widely adopted current protocols $[5,20]$.

When designing the tabulated guideline utilized by the 22 observers in this trial, it was clearly noted that the platform for the assessment of $\alpha \mathrm{S}$ pathology is essentially the same when assigning a Braak stage or a McKeith type $[5,20]$. Both strategies are based on the original work of Kosaka and colleagues [17] and assume that $\alpha \mathrm{S}$ pathology progresses in an orderly caudal to rostral direction. The main difference between these two commonly applied protocols is primarily in the selection of the regions to be assessed. In Braak's staging, the outcome is given as a stage of $\alpha \mathrm{S}$ pathology and in McKeith's typing a more generalized 'type' or anatomical category of $\alpha \mathrm{S}$ pathology is assigned [5, 20]. The 
Table 8 The most frequent Braak stage and McKeith type following original instructions [5, 20], instructions devised by BrainNet Europe (Fig. 5) and other previously published modifications of original instructions [18, 21]

\begin{tabular}{|c|c|c|c|c|c|c|c|c|c|c|c|c|}
\hline \multirow[t]{3}{*}{ Case } & \multicolumn{6}{|c|}{ Braak stage } & \multicolumn{6}{|c|}{ McKeith type } \\
\hline & \multicolumn{2}{|c|}{$\begin{array}{l}\text { Original }^{\mathrm{a}} \\
\text { (Table 1a) } \\
\text { Absolute } \\
\quad \text { agreement } \%\end{array}$} & \multicolumn{2}{|c|}{$\begin{array}{l}\text { Modified by } \\
\text { BNE }^{\text {b }} \text { (Fig. 5) } \\
\text { Absolute } \\
\quad \text { agreement } \%\end{array}$} & \multicolumn{2}{|c|}{$\begin{array}{l}\text { Simplified }^{\mathrm{c}} \text { by } \\
\text { Müller et al. } \\
\text { (Table } 1 \mathrm{~b} \text { ) } \\
\text { Absolute } \\
\quad \text { agreement \% }\end{array}$} & \multicolumn{2}{|c|}{$\begin{array}{l}\text { Original }^{\mathrm{d}} \\
\text { (Table 1c) } \\
\text { Absolute } \\
\quad \text { agreement } \%\end{array}$} & \multicolumn{2}{|c|}{$\begin{array}{l}\text { Modified by } \\
\text { BNE }^{\mathrm{e}} \text { (Fig. 5) } \\
\text { Absolute } \\
\quad \text { agreement \% }\end{array}$} & \multicolumn{2}{|c|}{$\begin{array}{l}\text { Modified }^{\mathrm{f}} \text { by } \\
\text { Leverenz et al. } \\
\text { (Table 1d) } \\
\text { Absolute } \\
\quad \text { agreement \% }\end{array}$} \\
\hline & Stage & Single case & Stage & Single case & Stage & Single case & Stage & Single case & Stage & Single case & Stage & Single case \\
\hline 1 & 1 & 95 & 1 & 100 & 1 & 100 & Brainstem & 100 & Brainstem & 100 & Brainstem & 100 \\
\hline 2 & 2 & $64 *$ & 2 & 95 & 2 & 95 & Brainstem & 100 & Brainstem & 100 & Brainstem & 100 \\
\hline 3 & 3 & $50 *$ & 3 & 82 & 3 & $64^{*}$ & Brainstem & 95 & Brainstem & 91 & Brainstem & 91 \\
\hline 4 & $3^{\mathrm{g}}$ & $77 *$ & 3 & 86 & 3 & 91 & Brainstem & 100 & Brainstem & 100 & Brainstem & 100 \\
\hline 5 & 3 & $59 *$ & 4 & $64 *$ & 3 & 86 & Brainstem & 91 & Limbic & 95 & Limbic & $68^{*}$ \\
\hline 6 & 3 & $64 *$ & 3 & $55^{*}$ & 3 & $59 *$ & Brainstem & 100 & Brainstem & 100 & Brainstem & 100 \\
\hline 7 & 4 & $59 *$ & 4 & $64 *$ & 3 & 82 & Brainstem & 86 & Limbic & $73^{*}$ & Limbic & $68^{*}$ \\
\hline 8 & 4 & $77 *$ & 4 & 86 & 3 & $59^{*}$ & Brainstem & $68 *$ & Limbic & 100 & Limbic & 100 \\
\hline 9 & 4 & $36^{*}$ & 5 & $55^{*}$ & 3 & 82 & Brainstem & $59 *$ & Limbic & 86 & Limbic & 82 \\
\hline 10 & 4 & $45^{*}$ & 4 & $68 *$ & 3 & $68^{*}$ & Brainstem & 82 & Limbic & 82 & Limbic & $73 *$ \\
\hline 11 & $4^{\mathrm{g}}$ & $45^{*}$ & 4 & $55^{*}$ & 3 & 91 & Brainstem & 91 & Limbic & $55^{*}$ & Limbic & $55^{*}$ \\
\hline 12 & $4^{\mathrm{g}}$ & $45^{*}$ & 5 & $41 *$ & 3 & 82 & Brainstem & $68 *$ & Limbic & 82 & Limbic & 95 \\
\hline 13 & 4 & 86 & 4 & 82 & 3 & 86 & Brainstem & $73 *$ & Limbic & 91 & Limbic & 95 \\
\hline 14 & $4^{\mathrm{h}}$ & $59 *$ & $5 / 6$ & $68 *$ & $5 / 6$ & $55^{*}$ & Limbic $^{\mathrm{h}}$ & 86 & Limbic & 86 & Limbic & $73 *$ \\
\hline 15 & 4 & $45^{*}$ & 4 & $64 *$ & 4 & $41^{*}$ & Limbic & 86 & Limbic & 82 & Limbic & $77 *$ \\
\hline 16 & $5 / 6$ & 86 & $5 / 6$ & 91 & $5 / 6$ & $64 *$ & Limbic & 86 & Neocortical & $64^{*}$ & Neocortical & $59^{*}$ \\
\hline 17 & $5 / 6^{\mathrm{g}, \mathrm{h}}$ & $68^{*}$ & $5 / 6$ & $68 *$ & 3 & $77^{*}$ & Limbic $^{\mathrm{h}}$ & 82 & Limbic & 95 & Limbic & 95 \\
\hline 18 & $5 / 6^{\mathrm{g}, \mathrm{h}}$ & $68 *$ & $5 / 6$ & 82 & 4 & $36^{*}$ & Limbic $^{\mathrm{h}}$ & 86 & Limbic & $55^{*}$ & Limbic & $64^{*}$ \\
\hline 19 & $5 / 6$ & 86 & $5 / 6$ & 95 & $5 / 6$ & $64 *$ & Limbic & 95 & Limbic & $68 *$ & Limbic & $68 *$ \\
\hline 20 & $5 / 6^{\mathrm{h}}$ & 95 & $5 / 6$ & 91 & $5 / 6$ & $68^{*}$ & Limbic $^{\mathrm{h}}$ & 86 & Limbic & $73 *$ & Limbic & $73 *$ \\
\hline 21 & $5 / 6$ & $64 *$ & $5 / 6$ & 100 & 3 & $73 *$ & Limbic & $55^{*}$ & Neocortical & $64 *$ & Neocortical & $59^{*}$ \\
\hline 22 & $5 / 6^{\mathrm{h}}$ & 82 & $5 / 6$ & 100 & $5 / 6$ & 100 & Limbic $^{\mathrm{h}}$ & $45^{*}$ & Limbic & $55^{*}$ & Limbic & $59 *$ \\
\hline 23 & $5 / 6^{\mathrm{g}, \mathrm{h}}$ & 100 & $5 / 6$ & 100 & $5 / 6$ & 100 & Limbic $^{\mathrm{h}}$ & $50 *$ & Neocortical & 82 & Neocortical & 82 \\
\hline 24 & $5 / 6^{\mathrm{g}}$ & $73 *$ & $5 / 6$ & 91 & $5 / 6$ & $45^{*}$ & Limbic & $64^{*}$ & Neocortical & $78 *$ & Neocortical & $64 *$ \\
\hline 25 & $5 / 6$ & 91 & $5 / 6$ & 95 & $5 / 6$ & 91 & Neocortical & $68^{*}$ & Neocortical & 86 & Neocortical & 86 \\
\hline 26 & $5 / 6$ & 100 & $5 / 6$ & 100 & $5 / 6$ & 100 & Neocortical & 100 & Neocortical & 100 & Neocortical & 100 \\
\hline 27 & $5 / 6$ & 100 & $5 / 6$ & 100 & $5 / 6$ & 100 & Neocortical & 95 & Neocortical & 100 & Neocortical & 100 \\
\hline 28 & $5 / 6$ & 100 & $5 / 6$ & 100 & $5 / 6$ & $77^{*}$ & Neocortical & $59 *$ & Neocortical & $77 *$ & Neocortical & $68^{*}$ \\
\hline 29 & $5 / 6$ & 86 & $5 / 6$ & 100 & $5 / 6$ & 91 & Neocortical & $64 *$ & Neocortical & 91 & Neocortical & 91 \\
\hline 30 & $5 / 6$ & 100 & $5 / 6$ & 100 & $5 / 6$ & 100 & Neocortical & 100 & Neocortical & 100 & Neocortical & 100 \\
\hline 31 & 6 & 100 & $5 / 6$ & 100 & $5 / 6$ & 95 & Neocortical & 91 & Neocortical & 95 & Neocortical & 95 \\
\hline $\mathrm{Abs}^{\mathrm{i}}$ & 74 & & 83 & & 78 & & 81 & & 84 & & 82 & \\
\hline $\mathrm{Abs}^{\mathrm{j}}$ & 73 & & 83 & & 79 & & 81 & & 86 & & 84 & \\
\hline $\mathrm{W}^{\mathrm{k}}$ & 0.000 & & 0.005 & & 0.001 & & 0.093 & & 0.230 & & 0.002 & \\
\hline $\mathrm{W}^{1}$ & 0.000 & & 0.000 & & 0.094 & & 0.526 & & 0.000 & & 0.000 & \\
\hline
\end{tabular}

Braak stage as given in ${ }^{a}$ Braak et al. 2003 [5], in ${ }^{b}$ Fig. 5 and in ${ }^{c}$ Müller et al. 2005 [21]. McKeith type as given in ${ }^{\text {d }}$ McKeith et al. 2005 [20], in ${ }^{\mathrm{e}}$ Fig. 5 and in ${ }^{\mathrm{f}}$ Leverenz et al. 2008 [18]. ${ }^{\mathrm{g}}$ IF case $=$ staging criteria incompletely fulfilled, ${ }^{\mathrm{h}}$ amygdala-predominant type. The absolute agreement in percent and significant differences $* p<0.05$ tested by means of the nonparametric Wilcoxon-rank-sum test are given for a single case, overall $\left(\mathrm{Abs}^{\mathrm{i},} \mathrm{W}^{\mathrm{k})}\right.$ and overall when amygdala predominant cases were excluded $\left(\mathrm{Abs}^{\mathrm{j}}, \mathrm{W}^{\mathrm{l}}\right)$

'brainstem type' of the McKeith's strategy largely corresponds to Braak stages 1-3, and the 'neocortical type' largely to Braak stages 5 and 6 . However, the 'limbic type' of the McKeith strategy can represent Braak stages $3-5$, if the assessment instructions are strictly followed $[5,20]$. 
There is much recent work confirming that the progression of $\alpha \mathrm{S}$ pathology is not as straightforward as originally presumed and there are several reports which highlight deviations in the orderly caudal to rostral progression pattern of pathology $[11,12,16,18,22,23,29,31]$. One likely reason why the Braak's original staging may yield poor inter-observer agreement is that the staging scheme requires that each subgroup displays newly affected regions and worsening impairment of those previously involved [5, 6]. With respects to the McKeith's typing, lack of clear differences between the three categories represents a major obstacle [20]. Thus, when strictly following the published instructions, a substantial number of cases remain unclassified, clearly indicating the need for a more universally applicable paradigm of $\alpha \mathrm{S}$ pathology [16, 18, 22, 23, 31].

In this study, applying the original McKeith's typing resulted in an overall inter-observer agreement of $81 \%$ which was lowest in the limbic type (73\%) [20]. It should be noted, however, that in $39 \%$ of the cases, less than $75 \%$ of the observers agreed on the specific type. Two observers used the McKeith's typing to assess 89 cases and achieved an even lower agreement (58\%), and concluded that a substantial number of their original 208 cases (49\%) were not classifiable [18]. However, they reported that by reducing the number of regions to be assessed, by adding an amygdala-predominant entity and by allowing more variability in the assessment of the severity of LB-related $\alpha \mathrm{S}$ pathology, they were able to categorise $97 \%$ of their cases $[18,20]$. They reported $87 \%$ agreement between the two assessors when following their modified criteria. The existence of the amygdala-predominant category was already acknowledged by Uchikado and colleagues in 2006 [29]. The 22 observers in the present study reached an $82 \%$ agreement when applying those modified criteria [18], a performance which was also achieved for the protocol newly designed by the BNE consortium (84\%) during the joint assessment meeting. Both the modified McKeith's typing [18] and the BNE protocol resulted in assignment of each case to the same category (i.e. brainstem, limbic or neocortical). The absolute agreement while applying the Leverenz strategy and the BNE protocol is here probably primarily due to the selection of material [18]. It should be noted that these two strategies are not fully comparable. In all included cases which were of neocortical type, substantial pathology was seen and thus the Leverenz criteria, i.e. $>1 \mathrm{LB} / \mathrm{high}$ power field and sparse neurites were fulfilled. The BNE-protocol does not require any assessment of the extent of pathology and thus some cases which are designated being of neocortical type following BNE-protocol ( $\alpha$ S-IR LBs seen) will fulfill the criteria for limbic type rather than neocortical while following the strategy described by Leverenz and colleagues [18]. It is noteworthy that the protocol designed by BNE resulted in only six cases where agreement was below $70 \%$ compared to ten cases following the recently modified McKeith's strategy [18]. It is noteworthy that $\alpha S$ pathology in a neuroanatomical region not included in the Leverenz modification but recommended for assessment in the BNE protocol may alter the result in specific cases [18]. Related issues around the variability of pathology within individual cases is therefore an important source of discrepancy, when comparing results obtained by different observers who may have followed different modifications of published assessment strategies. Furthermore, the clinical and pathophysiological significance of $\alpha \mathrm{S}$ pathology seen in various anatomic patterns is still unclear, as was recently stated in a critical reappraisal of Lewy related pathologies by Jellinger [14]. Based on the above, a reduction of regions to be assessed regarding $\alpha \mathrm{S}$ pathology is not advisable.

When the results obtained when following the original instructions published by McKeith and colleagues were compared to those obtained while following either the Leverenz modification or the BNE-protocol, it was noted that 12 cases were allocated to a more 'rostral' category (8 cases, brainstem $\rightarrow$ limbic; 4 cases, limbic $\rightarrow$ neocortical) $[18,20]$. These category shifts might be due to the lack of detail in the original published criteria. Leverenz and colleagues already noted that one of the pitfalls in the original publication was a lack of stringency, so that they recommended assigning a case that fulfilled criteria for two categories to the more anatomically rostral category. In contrast, the BNE-protocol permits cases to be assigned to only one category to avoid this confusion. The clinical implications of this shift to a more "rostral" neuropathological category need to be evaluated as both limbic and particularly neocortical types are considered to be evidence of a more severe symptomatology.

When the original Braak protocol was applied, then only a 65\% agreement was reached in the staging of $\alpha \mathrm{S}$ pathology with the agreement being as low as $32 \%$ in some cases. Only in cases in stages 1 or 6 was agreement high. Two issues influenced this outcome. The variability within each stage was extensive in those cases where the pathology lay outside the hypothetical pattern of caudal to rostral progression and also in cases with amygdala-predominant pathology. Taking these two issues into account, the agreement increased only from 65 to $67 \%$. When stages 5 and 6 were combined as in Table 8 , the percentages were still below $80 \%$ ( 74 respective 77). Previously, it was reported that a high agreement could be reached following a slightly modified Braak protocol when staging $\alpha \mathrm{S}$ pathology in 21 cases by 6 observers [21]. We also applied the strategy described by Müller and colleagues and achieved $78 \%$ agreement in the assessments and the agreement increased to $79 \%$ when the six cases of amygdala-predominant synucleinopathy were excluded. However, in our study, the results obtained while applying 
the strategy described by Müller and colleagues differed significantly from those obtained when applying the original strategy described by Braak and colleagues and those obtained when applying the BNE-protocol. In a substantial number of cases, the Müller modification resulted in assignment to a lower stage $[5,21]$. This difference is primarily due to the reduced number of neuroanatomical regions assessed by Müller and colleagues compared to the original Braak protocol $[5,21]$. Furthermore, on an individual case level, the inter-observer agreement differed significantly in 14 cases when compared to 10 cases when applying the BNE protocol.

Already in 2006, Uchikado and colleagues [29] noted while assessing LB pathology in subjects with Alzheimer's disease that in some cases an amygdala predominant distribution of $\alpha \mathrm{S}$ pathology was noted. Later, in 2008 Leverenz and colleagues [18] proposed the addition of an amygdala predominant category to permit a reliable classification. Here, we also noted that the addition of an amygdala-predominant category increased the inter-observer agreement.

Using the nine-block strategy (Fig. 5) proposed by the BNE protocol, not only is it possible to robustly assign the $\alpha \mathrm{S}$ pathology type, but also a more detailed stage of $\alpha \mathrm{S}$ pathology can be ascribed. Thus, this method is applicable both to diagnostic and research use. For molecular-biological, biochemical or detailed clinico-pathological studies, we recommend that the $\alpha \mathrm{S}$ stages from 0 to 6 and the assignment to a amygdala-predominant category will be most appropriate, whereas for routine diagnostic purposes a more generalized assignment to brainstem, limbic, neocortical or amygdala-predominant categories may be sufficient.

The sampling strategy recommended by BNE and recommended in the original strategies described by Braak and colleagues [5] and McKeith [20] and colleagues do not include the olfactory bulb that has been indicated to be affected at an early stage in both Alzheimer's disease [10] and of PD and DLB [9]. It is, however, relevant to consider whether this structure, contrary to current general practise in diagnostic neuropathology, should be routinely sampled for assessment of neurodegenerative lesions, particularly when dealing with unimpaired aged subjects. Recently, the significance of $\alpha \mathrm{S}$ pathology in the olfactory bulb in subjects with DLB was brought forward by Beach and colleagues [4]. The sensitivity and specificity of $\alpha \mathrm{S}$ pathology in the olfactory bulb for PD and DLB were over $90 \%$ and thus the authors concluded that $\alpha \mathrm{S}$ pathology accurately predicted the presence of $\alpha \mathrm{S}$ pathology in other brain regions [4]. They even suggested that olfactory bulb biopsy should be considered as a diagnostic tool particularly in subjects being assesses for surgical therapy. This approach was further discussed by others as some negative biopsy studies regarding $\alpha \mathrm{S}$ pathology in the olfactory bulb have also been reported [15, 24]. Recently, Sengoku and colleagues [27] assessed 320 consecutive autopsies which showed $\alpha \mathrm{S}$ pathology in $32.9 \%$. However, the olfactory bulb was involved in only $26.6 \%$ further emphasising that involvement of the olfactory bulb is not seen in all cases with $\alpha \mathrm{S}$ pathology in the central nervous system.

The novel BNE-protocol for designation of both the stage and the type of $\alpha \mathrm{S}$ pathology is based on the assessment of $\alpha \mathrm{S}$-IR in 13 defined neuroanatomical regions in conjunction with the type of lesions (i.e. LB or LN). This strategy was devised to avoid one major problem in the validation of inter-observer methods for evaluating neurodegenerative pathology, i.e. the use of numerical counting of lesions. Previous studies dealing with the assessment of $\alpha \mathrm{S}$ pathology have indicated that it is difficult to achieve satisfactory agreement on the severity of pathology in even a core sample of only $2 \mathrm{~mm}$ diameter [2]. It was concluded that since quantitative estimates of $\alpha \mathrm{S}$-IR structures are unreliable, these should not be included in the assessment strategy. It is also evident that differing staining methods for $\alpha \mathrm{S}$ pathology yield variable results $[2,3,8]$. Thus, a standard validated protocol for typing and staging pathology does require a consistent quality in the stained sections and an assessment method that delivers reproducible results.

In conclusion, here we report a protocol for assessing $\alpha \mathrm{S}$ pathology, based on a modification of the existing widely adopted methods that can achieve a high inter-observer agreement for both the assignment to brainstem, limbic, neocortical and amygdala-predominant categories of synucleinopathy and the Braak stages (1-6) when appropriate. Due to its simplicity, when these BNE-protocols were applied, it was possible for all cases to be classified, i.e. by evaluating nine brain regions and only assessing the presence or absence of $\alpha \mathrm{S}-\mathrm{IR}$ LBs and LNs.

Acknowledgments We thank Mrs. Tarja Kauppinen, Mrs. Merja Fali, Mr. Heikki Luukkonen and Mr Hannu Tiainen for technical assistance and Ewen MacDonald for critical reading of the manuscript. This study was supported by European Union grant FP6: BNEII No LSHM-CT-2004-503039. This article reflects only the authors' views and the Community is not liable for any use that may be made of the information contained therein. The study has been authorized by the Ethics Committee of Kuopio University Hospital.

Open Access This article is distributed under the terms of the Creative Commons Attribution Noncommercial License which permits any noncommercial use, distribution, and reproduction in any medium, provided the original author(s) and source are credited.

\section{References}

1. Alafuzoff I, Arzberger T, Al-Sarraj S et al (2008) Staging of neurofibrillary pathology in Alzheimer's Disease. A study of the BrainNet Europe Consortium. Brain Pathol 18:484-496 
2. Alafuzoff I, Parkkinen L, Al-Sarraj S et al (2008) Assessment of immunohistochemically detectable $\alpha$-synuclein pathology. A study of the BrainNet Europe Consortium. J Neuropathol Exp Neurol 67:125-143

3. Beach TG, White CL, Hamilton RL et al (2008) Evaluation of $\alpha$ synuclein immunohistochemical methods used by invited experts. Acta Neuropathol 116:277-288

4. Beach TG, White CLIII, Hladik CL et al (2009) Olfactory bulb $\alpha$-synucleinopathy has high specificity and sensitivity for Lewy body disorders. Acta Neuropathol 117:169-174

5. Braak H, Del Tredici K, Rub U, de Vos RA, Jansen Steur EN, Braak E (2003) Staging of brain pathology related to sporadic Parkinson's disease. Neurobiol Aging 24:197-211

6. Braak H, Bohl JR, Muller CM, Rub U, deVos RA, Del Tredici K (2006) Stanley Fahn lecture 2005: the staging procedure for the inclusion body pathology associated with sporadic Parkinson's disease reconsidered. Mov Disorders 21:2042-2051

7. Braak H, Alafuzoff I, Arzberger T, Kretzschmar H, Del Tredici K (2006) Staging of Alzheimer disease-associated neurofibrillary pathology using paraffin sections and immunohistochemistry. Acta Neuropathol 112:389-404

8. Croisier E, MRes DE, Deprez M et al (2006) Comparative study of commercially available anti- $\alpha$-synuclein antibodies. Neuropathol Appl Neurobiol 32:351-356

9. Del Tredici K, Rub U, De Vos RA, Bohl JR, Braak H (2002) Where does Parkinson disease pathology begin in the brain? J Neuropathol Exp Neurol 61:413-426

10. Esiri MM, Wilcock GK (1984) The olfactory bulbs in Alzheimer's disease. J Neurol Neurosurg Psychiatry 47:56-60

11. Hamilton RL (2000) Lewy bodies in Alzheimer's disease: a neuropathological review of 145 cases using alpha-synuclein immunohistochemistry. Brain Pathol 10:378-384

12. Hishikawa N, Hashizume Y, Yoshida M, Sobue G (2003) Clinical and neuropathological correlates of Lewy body disease. Acta Neuropathol 105:341-350

13. Ince PG, Perry EK, Morris CM (1998) Dementia with Lewy bodies. A distinct non-Alzheimer dementia syndrome? Brain Pathol 8:299-324

14. Jellinger KA (2008) A critical reappraisal of current staging of Lewy-related pathology in human brain. Acta Neuropathol 116:1-16

15. Jellinger KA (2009) Olfactory bulb $\alpha$-synucleinopathy has high specificity and sensitivity for Lewy body disorders. Acta Neuropathol 117:215-216

16. Kalaitzakis ME, Graeber MB, Gentleman SM, Pearce RK (2008) The dorsal motor nucleus of the vagus is not an obligatory trigger site of Parkinson's disease: a critical analysis of $\alpha$-synuclein staging. Neuropathol Appl Neurobiol 34:284-295

17. Kosaka K, Yoshimura M, Ikeda K, Budka H (1984) Diffuse type of Lewy body disease: progressive dementia with abundant cortical Lewy Bodies and senile changes of varying degree-a new disease? Clin Neuropathol 3:185-192
18. Leverenz JB, Hamilton R, Tsuang DW et al (2009) Empiric refinement of the pathologic assessment of Lewy-related pathology in the dementia patients. Brain Pathol 18:220-224

19. McKeith IG, Galasko D, Kosaka K et al (1996) Consensus guidelines for the clinical and pathologic diagnosis of dementia with Lewy Bodies (DLB): report of the consortium on DLB international workshop. Neurology 47:1113-1124

20. McKeith IG, Dickson DW, Lowe J (2005) Consortium on DLB Diagnosis and management of dementia with Lewy bodies: third report of the DLB consortium. Neurology 65:1863-1872

21. Müller CM, de Vos RAI, Maurage C-A, Thal DR, Tolnay M, Braak H (2005) Staging of Parkinson disease-related $\alpha$-synuclein pathology: inter- and intra-rater reliability. J Neuropathol Exp Neurol 64:623-628

22. Parkkinen L, Soininen H, Alafuzoff I (2003) Regional distribution of $\alpha$-synuclein pathology in unimpaired aging and Alzheimer's disease. J Neuropathol Exp Neurol 62:363-367

23. Parkkinen L, Pirttilä T, Alafuzoff I (2008) Applicability of current staging/categorization of $\alpha$-synuclein pathology and their clinical relevance. Acta Neuropathol 115:399-407

24. Parkkinen L, Silveira-Moriyama L, Holton JL, Lees AJ, Revesz T (2009) Can olfactory bulb biopsy be justified for the diagnosis of Parkinson's disease ? Comments on "olfactory bulb $\alpha$-synucleinopathy has high specificity and sensitivity for Lewy body disorders". Acta Neuropathol 117:213-214

25. Perry RH, Irving D, Blessed G, Fairbain A, Perry EK (1999) Senile dementia of Lewy body type A clinical and neuropathologically distinct form of Lewy body dementia in the elderly. J Neurol Sci 95:119-139

26. Polymeropoulos MH, Lavedan C, Leroy E et al (1997) Mutation in the alpha-synuclein gene identified in families with Parkinson's disease. Science 276:2045-2047

27. Sengoku R, Saito Y, Ikemura M, Hatsuta H, Sakiyama Y, Kanemura K, Arai T, Sawabe M, Tanaka N, Mochizuki H, Inoue K, Murayama S (2008) Incidence and extent of Lewy body related alpha-synucleinopathy in aging human olfactory bulb. J Neuropathol Exp Neurol 67:1072-1083

28. Spillantini MG, Schmidt ML, Lee VM, Trojanowski JQ, Jakes R, Goedert M (1997) Alpha-synuclein in Lewy bodies. Nature 388:839-840

29. Uchikado H, Lin WL, DeLucia MW, Dickson DW (2006) Alzheimer disease with amygdala Lewy bodies: a distinct form of alpha-synucleinopathy. J Neuropathol Exp Neurol 65:685-697

30. Ueda K, Fukushima H, Masliah E (1993) Molecular cloning of cDNA encoding an unrecognizable component of amyloid in Alzheimer's disease. Proc Natl Acad Sci USA 90:11282-11286

31. Zaccai J, Brayne C, McKeith I, Matthews F, Ince PG (2008) Patterns of stages of $\alpha$-synucleinopathy. Relevance in a population-based cohort. Neurology 70:1042-1048 